Article

\title{
Estimated Impacts of Climate Change on Eddy Meridional Moisture Transport in the Atmosphere
}

\section{Sergei Soldatenko}

St. Petersburg Institute for Informatics of the Russian Academy of Sciences, Laboratory of Applied Informatics, 14-th Line, No. 39, St. Petersburg 199178, Russia; soldatenko@iias.spb.su; Tel.: +7-931-354-0598

Received: 28 October 2019; Accepted: 17 November 2019; Published: 20 November 2019

\begin{abstract}
Research findings suggest that water (hydrological) cycle of the earth intensifies in response to climate change, since the amount of water that evaporates from the ocean and land to the atmosphere and the total water content in the air will increase with temperature. In addition, climate change affects the large-scale atmospheric circulation by, for example, altering the characteristics of extratropical transient eddies (cyclones), which play a dominant role in the meridional transport of heat, moisture, and momentum from tropical to polar latitudes. Thus, climate change also affects the planetary hydrological cycle by redistributing atmospheric moisture around the globe. Baroclinic instability, a specific type of dynamical instability of the zonal atmospheric flow, is the principal mechanism by which extratropical cyclones form and evolve. It is expected that, due to global warming, the two most fundamental dynamical quantities that control the development of baroclinic instability and the overall global atmospheric dynamics - the parameter of static stability and the meridional temperature gradient (MTG) - will undergo certain changes. As a result, climate change can affect the formation and evolution of transient extratropical eddies and, therefore, macro-exchange of heat and moisture between low and high latitudes and the global water cycle as a whole. In this paper, we explore the effect of changes in the static stability parameter and MTG caused by climate change on the annual-mean eddy meridional moisture flux (AMEMF), using the two classical atmospheric models: the mid-latitude $f$-plane model and the two-layer $\beta$-plane model. These models are represented in two versions: "dry," which considers the static stability of dry air alone, and "moist," in which effective static stability is considered as a combination of stability of dry and moist air together. Sensitivity functions were derived for these models that enable estimating the influence of infinitesimal perturbations in the parameter of static stability and MTG on the AMEMF and on large-scale eddy dynamics characterized by the growth rate of unstable baroclinic waves of various wavelengths. For the base climate change scenario, in which the surface temperature increases by $1{ }^{\circ} \mathrm{C}$ and warming of the upper troposphere outpaces warming of the lower troposphere by $2{ }^{\circ} \mathrm{C}$ (this scenario corresponds to the observed warming trend), the response of the mass-weighted vertically averaged annual mean MTG is $-0.2{ }^{\circ} \mathrm{C}$ per $1000 \mathrm{~km}$. The dry static stability increases insignificantly relative to the reference climate state, while on the other hand, the effective static stability decreases by more than $5.4 \%$. Assuming that static stability of the atmosphere and the MTG are independent of each other (using One-factor-at-a-time approach), we estimate that the increase in AMEMF caused by change in MTG is about 4\%. Change in dry static stability has little effect on AMEMF, while change in effective static stability leads to an increase in AMEMF of about $5 \%$. Thus, neglecting atmospheric moisture in calculations of the atmospheric static stability leads to tangible differences between the results obtained using the dry and moist models. Moist models predict $~ 9 \%$ increase in AMEMF due to global warming. Dry models predict $\sim 4 \%$ increase in AMEMF solely because of the change in MTG. For the base climate change scenario, the average temperature of the lower troposphere (up to $\sim 4 \mathrm{~km}$ ), in which the atmospheric moisture is concentrated, increases by $\sim 1.5^{\circ} \mathrm{C}$. This leads to an increase in specific humidity of about $10.5 \%$. Thus, since both AMEMF and atmospheric water vapor content increase due to the influence of climate change, a rather noticeable restructuring of the global water cycle is expected.
\end{abstract}


Keywords: climate change; hydrological (water) cycle; moisture transport; baroclinic instability; atmospheric transient eddies

\section{Introduction}

Acceleration in the rate of changes to the earth's climate system (ECS) that have been observed around the globe and its different geographical regions since the early 20th century has become unprecedented over recent decades [1]. The evidence for rapid and dramatic climate change encompasses increasing the planet's average surface temperature, rising global sea level, reducing glacier net volumes, decreasing polar ice sheets and sea ice extent, changing heat stores in the ocean, changing rainfall patterns, and a range of other effects. The Fifth Assessment Report of the Intergovernmental Panel on Climate Change (IPCC) states that "Human influence has been detected in warming of the atmosphere and oceans, in changes in the global water cycle, in reductions in snow and ice, in global mean sea level rise, and in changes in some climatic extremes" [1]. One of the clearest indicators of climate change is the rise in global average surface temperature. According to the latest World Meteorological Organization's (WMO) report "Statement on the State of the Global Climate in 2018" published on March 2019 [2], "The global mean temperature for 2018 is estimated to be $0.99 \pm 0.13^{\circ} \mathrm{C}$ above the preindustrial baseline (1850-1900)." It is important that over two-third of that global mean temperature increase has occurred after 1980. This WMO's document also points out that other key climate change indicators (e.g., global mean sea level, Arctic and Antarctic sea-ice extent, greenhouse gas concentrations, extreme natural events) have become even more pronounced. The main cause of the current climate change is human activities and, above all, human-induced substantial emissions of greenhouse gases (GHG) into the atmosphere [1].

Research findings suggest that the shift to a warmer climate is accompanied by intensification of the hydrological (or water) cycle [1,3-11] that describes the global circulation of water in its solid, liquid, and gas phases throughout the four geospheres (atmosphere, hydrosphere, lithosphere, and biosphere). The main physical processes that form the planetary hydrological cycle involve evaporation of water (mainly from the ocean surface to the atmosphere), condensation of atmospheric water vapor, multi-scale horizontal moisture transport (advection), precipitation that can take on different forms (e.g., rain, snow, ice crystals), runoff and snowmelt, interception, infiltration, transpiration, percolation, and storage. The hydrological cycle intensifies under global warming mainly because the amount of water that evaporates from the ocean and land to the air and the total water vapor content in the atmosphere will increase with temperature. Theoretical estimates and satellite observations suggest that as air temperature increases the saturated water vapor pressure increases as well by about $7 \%$ per Kelvin $[5,12,13]$. Indeed, let us write the approximate Clausius-Clapeyron relation assuming the latent heat of vaporization $L_{w}$ is a constant:

$$
\frac{d \ln e_{s}}{d T}=\frac{L_{v}}{R_{v} T^{2}}
$$

According to this equation, an infinitesimal change in temperature $\Delta T$ is accompanied by a fractional change $\Delta e_{s} / e_{s}$ in saturation vapor pressure of:

$$
\frac{\Delta e_{s}}{e_{s}} \approx \frac{L_{v}}{R_{v} T^{2}} \Delta T
$$

Taking the value of $T_{0}=273.16 \mathrm{~K}$ as a reference temperature, we obtain that the fractional growth in $e_{s}$ is $\sim 7 \% \mathrm{~K}^{-1}$, meaning that to increase the temperature by $1 \mathrm{~K}$ results in the $7 \%$ increase in saturation vapor pressure. The observations also indicate that over the last two to three decades the precipitation has increased at about the same rate [12]. Since the hydrological cycle has a significant impact on the climate of our planet, its strengthening with rising global temperature may alter the weather patterns worldwide. Changes in frequency and intensity of extreme weather events (e.g., storms), 
precipitation, heavy rainfall, and flooding are the potential impacts of an intensified water cycle. However, the potential future alterations in the earth's climate and weather conditions in response to the human-induced planet's warming will not be geographically homogeneous [1]. Some parts of the world will experience more pronounced changes, but some regions will experience less noticeable changes. In particular, main characteristics of rainfall and other forms of precipitation (their amount, intensity and frequency) will experience strong spatial variations [14]. Greater volume of precipitation is expected in high latitude regions and in the tropics, while in subtropical arid and semi-arid regions and many mid-latitude regions rainfall amounts will decrease [1,15-18]. Consequently, geographical areas with increased amount, intensity and frequency of precipitation and, moreover, areas that will also be seriously affected by sea level rise (coastal areas), will likely to experience increased risk of hazardous hydrological events, such as flooding.

The spatial and temporal heterogeneity of climate change (variations in the trend (cooling or warming) and magnitude of climate change over space) is determined not only by the geographic location of the region in question, but also by the general circulation of the atmosphere (GCA) which involves a wealth of air motions with scales on the order of thousands of kilometers such as the westerly mean flow in the mid-latitudes in both the northern and southern hemispheres, planetary waves, large-scale extratropical transient eddies (cyclones and anticyclones), monsoons, and trade winds [19-24]. One of the main dynamical mechanisms leading to the meridional transport of heat, moisture, and momentum from the tropical to polar latitudes and, thereby to the global redistribution of atmospheric moisture, are the large-scale extratropical eddies (cyclones) [19-22]. The so-called "atmospheric rivers" that transport water vapor outside of the tropics through the extratropics (middle latitudes) are associated with mid-latitude cyclonic eddies and their frontal zones $[25,26]$. Recent studies have indicated an increase in intensity of extratropical cyclones and a decrease in their frequency [27-34]. Baroclinic instability, a specific type of dynamical instability of the zonal atmospheric flow with the equator-to-pole (meridional) temperature contrast (gradient) and, therefore, with a vertical wind shear (thermal wind), in the field of Coriolis force, is the principal mechanism by which extratropical cyclones form and evolve [35-38]. The infinitesimal perturbations growing in such a flow derive their energy from the transformation of mean available potential energy (MAPE) which, in turn, depends on the tropospheric meridional temperature gradient (MTG); the larger the temperature differences between the equator and the pole, the greater the MAPE [39-41]. However, MTG is not the only fundamental parameter that determines the development of baroclinic instability in the atmosphere and, therefore, the formation of extratropical large-scale cyclonic eddies. The effective static stability of the atmosphere plays an equally important role in the generation of cyclones (e.g., [42-45]). Unlike the so-called "dry static stability" of the atmosphere [21], the effective static stability takes into consideration not only the vertical thermal stratification of the air (temperature lapse rate $\Gamma=-\partial T / \partial z$, where $T$ is an air temperature, and $z$ is a vertical coordinate), but also the effects of water vapor condensation, namely latent heat released into the atmosphere when the water vapor changes its state to a liquid. In consequence of latent heating, the effective stability of the moist atmosphere in mid-latitudes is less than the static stability of the dry atmosphere by about $40 \%$ [45]. It should be emphasized that the latent heat energy also affects the formation and development of extratropical cyclones contributing to their intensification (e.g., [46-50]).

Results of climate simulations and observational data indicate changes in atmospheric thermodynamics and large-scale circulations that have become especially apparent in recent decades (e.g., [51-56]). However, human-induced tropospheric warming is not uniform across the globe [1]. The most prominent warming is observed in the northern polar region near the surface (polar amplification phenomenon $[57,58]$ ) and at the upper equatorial troposphere implying changes in both static stability and MTG [59]. As a result of this warming, static stability increases in mid-latitude and tropical areas and decreases in polar areas [59-62]. In turn, the MTG increases in the higher altitudes and decreases at the surface which can provide, respectively, favorable and adverse conditions for the formation of large-scale extratropical eddies $[52,56,59,63,64]$. Thus, with global warming, static 
stability and MTG are expected to undergo certain changes affecting the formation and evolution of transient extratropical eddies, which will impact the heat and moisture macro-exchange between low and high latitudes, and, thereof, the earth's hydrological cycle.

In this paper, we explore the effect of changes in the static stability parameter and MTG caused by climate change on the annual-mean eddy meridional moisture flux (AMEMF), using the two classical atmospheric models: the mid-latitude $f$-plane model [36] and the two-layer $\beta$-plane model [37]. These models are represented in two versions: "dry," which considers the static stability of dry air alone, and "moist," in which effective static stability is considered as a combination of stability of dry and moist air together. Sensitivity functions were derived for these models that enable estimating the influence of infinitesimal perturbations in the parameter of static stability and MTG on the AMEMF and on large-scale eddy dynamics characterized by the growth rate of unstable baroclinic waves of various wavelength.

\section{Materials and Methods}

\subsection{Moisture Content and Transport in the Global Atmosphere}

Earth's climate system is made up of five basic parts: the atmosphere, hydrosphere, cryosphere, lithosphere, and biosphere, which interact with each other evolving over time and responding to internal and external perturbations. All the water on the earth form the hydrosphere which is commonly called "the water shell of our planet." Estimates indicate that the aggregated volume of water on earth is around $1.38 \times 10^{9} \mathrm{~km}^{3}[65,66]$. The prevailing portion of this, $1.34 \times 10^{9} \mathrm{~km}^{3}$ (about $97 \%$ of the total volume), is in the oceans. Oceans form the largest water reservoir on earth. The second largest global water reservoir includes ice sheets, sea ice, and glaciers containing a total of about $23 \times 10^{6}$ $\mathrm{km}^{3}\left(\sim 1.7 \%\right.$ of total planetary volume of water) followed by groundwater $\left(\sim 18 \times 10^{6} \mathrm{~km}^{3}\right.$ of water or $\sim 1.3 \%$ of the total volume). Apart from that, much smaller volumes of water are contained in lakes, rivers, and streams $\left(\sim 18 \times 10^{4} \mathrm{~km}^{3}\right.$ of water or $\sim 0.013 \%$ of the total volume) and in the atmosphere $\left(\sim 13 \times 10^{3} \mathrm{~km}^{3}\right.$ of water or $\sim 0.00094 \%$ of the total volume) $[65,66]$.

In the atmosphere, the volumetric water vapor content varies almost from zero to $4 \%$, and considerably changes across the globe and is subject to seasonal influence. The content of water vapor reaches its maximum at the earth's surface and decreases rapidly with height. For example, at an altitude of $5 \mathrm{~km}$, the water vapor content is nearly ten times less than that of the earth's surface, and at an altitude of $8 \mathrm{~km}$-one hundred times less. Thus, above $10-15 \mathrm{~km}$, the content of water vapor in the air is negligible [67]. Despite the fact that the amount of water contained in the atmosphere is much less than the total available water on earth, it would be very difficult to overestimate the key role of atmospheric water vapor in forming the energy balance of our planet and global hydrological cycle [68-70].

Water vapor along with carbon dioxide, methane, and ozone, forms the group of the major atmospheric GHGs [1]. Most likely that if there were no GHGs in the earth atmosphere, then our planet would hardly have been inhabited by humans. In fact, the water vapor is the most crucial natural GHG that is responsible for more than $60 \%$ of the total earth's greenhouse effect [71]. The positive feedback of water vapor in climate system is well-known; an increase in the atmospheric temperature caused by other factors increases water evaporations from oceans, lakes, rivers, and soil leading to rising concentrations of water vapor in the atmosphere and consequently increasing the greenhouse effect [1]. On the other hand, growing moisture content in the atmosphere contributes to the formation of cloud cover, which, in turn, reflects shortwave solar radiation, thereby increasing the planetary albedo. This leads to an anti-greenhouse effect [72]. Thus, the effect of atmospheric moisture on climate processes is complex and of varied nature.

In analyzing the global distribution and transport of moisture in the atmosphere, the balance equation can be written as [73]:

$$
\frac{\partial W}{\partial t}+\nabla \cdot \mathbf{Q}=E-P
$$


Here $W$ is the amount of precipitable water within the atmospheric column extending above the earth's surface of unit area, $\mathbf{Q}$ is the vertically integrated horizontal moisture flux, $E$ is the rate of evaporation, and $P$ is the rate of precipitation from the atmospheric column. Note that

$$
\begin{aligned}
& W=\frac{1}{g} \int_{0}^{p_{0}} q d p \\
& \mathbf{Q}=\int_{0}^{p_{0}} q \mathbf{V} \frac{d p}{g}=\underbrace{\mathbf{i}_{\lambda} \int_{0}^{p_{0}} q u \frac{d p}{g}}_{\text {Zonal component } Q_{\lambda}}+\underbrace{\mathbf{i}_{\varphi} \int_{0}^{p_{0}} q v \frac{d p}{g}}_{\text {Meridional component } Q_{\varphi}}
\end{aligned}
$$

In this study, the quantity of interest is the mean vertically integrated meridional moisture flux (MMF) $\bar{Q}_{\varphi}$, which can be decomposed into three components [73]:

$$
\underbrace{\{[\overline{\mathrm{qv}}]\}}_{\mathrm{MMF}}=\{\underbrace{\{[\bar{q}][\bar{v}]\}}_{\mathrm{MMC}}+\underbrace{\left\{\left[\overline{\bar{q}^{*}} \vec{v}^{*}\right]\right\}}_{\mathrm{SE}}+\underbrace{\left\{\left[\overline{q^{\prime} v^{\prime}}\right]\right\}}_{\mathrm{TE}}
$$

The first term on the right-hand side of this equation (MMC) is the contribution from mean meridional circulation, the second term (SE) is from stationary eddies (planetary waves), and the third term (TE) is from transient eddies (extratropical cyclones) $[67,68]$. Numerous studies involving the evaluation of the right-hand side of Equation (4) with observations datasets and CGCM-simulated data (Coupled atmosphere-ocean general circulation model) have shown that transient eddies dominate meridional moisture transport at mid-latitudes: $\sim 80 \%$ between $30^{\circ}$ and $40^{\circ}$ north and south latitudes (e.g., $[20,40,41,68,73-77])$. One can easily show that for the plane wave solutions (A15), the TE meridional moisture flux is exponentially dependent on the growth rate $\chi_{k}=k c_{i}$ of unstable modes [78]. Let $L_{w}$ be the wavelength of a baroclinic unstable wave and $k=2 \pi / L_{w}$ its wavenumber. Then

$$
q^{\prime}(x, p, t)=\mathfrak{R} e\left(\hat{q}(p) e^{i k(x-c t)}\right), v^{\prime}(x, p, t)=\mathfrak{R} e\left(\hat{v}(p) e^{i k(x-c t)}\right)
$$

or

$$
\begin{aligned}
& q^{\prime}(x, p, t)=|\hat{q}(p)| \cos \left[k\left(x-c_{r} t\right)+\theta_{q}(p)\right] e^{k c_{i} t} \\
& v^{\prime}(x, p, t)=|\hat{v}(p)| \cos \left[k\left(x-c_{r} t\right)+\theta_{v}(p)\right] e^{k c_{i} t}
\end{aligned}
$$

where $|\hat{q}(p)|$ and $|\hat{v}(p)|$ are the absolute values and $\theta_{q}(p)$ and $\theta_{v}(p)$ are the arguments of the complex values $\hat{q}(p)$ and $\hat{v}(p)$ respectively, $c_{r}=\mathfrak{R} e(c), c_{i}=\mathfrak{J} m(c)$.

The meridional equator-to-pole moisture flux averaged over one period of the unstable wave with wavelength $L_{w}$ is as follows [21]:

$$
{\overline{q^{\prime} v^{\prime}}}^{x}=\frac{1}{L_{w}} \int_{0}^{L_{w}} q^{\prime}(x, p, t) v^{\prime}(x, p, t) d x
$$

We can find the flux ${\overline{q^{\prime} v^{\prime}}}^{x}$ by substituting (6) and (7) into (8) and assuming the periodic boundary conditions along the $x$ axis: 


$$
\begin{gathered}
{\overline{q^{\prime} v^{\prime}}}^{x}=\frac{k}{2 \pi} \mathrm{e}^{2 k c_{i} t} \int_{0}^{2 \pi / k}|\hat{q}(p)| \cos \left[k\left(x-c_{r} t\right)+\theta_{q}(p)\right]|\hat{v}(p)| \cos \left[k\left(x-c_{r} t\right)+\theta_{u}(p)\right] d x \\
=\frac{k}{2 \pi} \mathrm{e}^{2 k c_{i} t} \int_{0}^{2 \pi / k}|\hat{q}(p) \| \hat{v}(p)| \cos \left[\theta_{q}(p)-\theta_{u}(p)\right] d x \\
\begin{array}{r}
+\frac{k}{2 \pi} \mathrm{e}^{2 k c_{i} t} \int_{0}^{2 \pi / k}|\hat{q}(p)||\hat{v}(p)| \cos \left[2 k\left(x-c_{r} t\right)+\theta_{q}(p)+\theta_{u}(p)\right] d x \\
=\frac{1}{2}|\hat{q}(p) \| \hat{v}(p)| \cos \left[\theta_{q}(p)-\theta_{u}(p)\right] \mathrm{e}^{2 k c_{i} t} \\
=\frac{1}{2} \mathfrak{R} e\left(\hat{q}(p) \hat{v}^{*}(p)\right) \mathrm{e}^{2 k c_{i} t}
\end{array}
\end{gathered}
$$

The product $k c_{i}=\chi_{k}$ with dimension day ${ }^{-1}$ is referred to as the growth rate of a baroclinic unstable wave with wavenumber of $k$. From the above equation, it follows that the growth rate $\chi_{k}$ significantly affects the meridional eddy moisture transport in the atmosphere. Global warming enhances this effect since, as mentioned in the introduction, an increase in temperature leads to an increase in water vapor content in the atmosphere. We should note that the growth rate $\chi_{k}$ depends upon the two variables, wavenumber $k$ (or wavelength $L_{w}$ ) of the unstable wave, and imaginary part of the phase speed $c_{i}$. Thus, the influence of changes in both $L_{w}$ and $c_{i}$ on $\chi_{k}$ will be explored below.

\subsection{Sensitivity Functions for Estimating the Influence of Global Warming on the Grouth Rate of Unstable Waves}

To estimate the influence of global warming on the growth rate of unstable baroclinic waves, let us consider the expression for $\chi_{k}$ valid for the $f$-plane model (see Equation (A23) in the Appendix A.2):

$$
\chi_{k}=\frac{\Lambda f_{0}}{2 \sqrt{\sigma_{0}}} \sqrt{\left|\eta^{2}-4(\eta \operatorname{coth} \eta-1)\right|}
$$

where $\eta=p_{0} k \sqrt{\sigma_{0}} / f_{0}$.

This equation shows that at a given latitude, the growth rate $\chi_{k}$ is dependent on a vertical wind shear $\Lambda$, static stability $\sigma_{0}$, and quantity $\eta$ which, in turn, depends on the static stability $\sigma_{0}$ and horizontal wavenumber $k$. As we discussed above, with global warming both the atmospheric static stability and the vertical wind shear, via MTG, are changed and by this way influence the development of baroclinic instability. Thus, the impact of climate change on $\chi_{k}$ can be estimated via variations in $\sigma_{0}$ and $\Lambda$ around their certain reference values $\sigma_{0}^{r e f}$ and $\Lambda^{r e f}$, which correspond to the current climate conditions [79]. Let $\delta \sigma_{0}$ and $\delta \Lambda$ be infinitesimal perturbations in the parameters $\sigma_{0}$ and $\Lambda$ caused by climate change. Note that $\delta \sigma_{0} \ll \sigma_{0}^{r e f}$ and $\delta \Lambda \ll \Lambda^{r e f}$. To quantify the effect of small perturbations $\delta \sigma_{0}$ and $\delta \Lambda$ on the growth rate $\chi_{k}$, we shall use the sensitivity functions $S_{\sigma}$ and $S_{\Lambda}$ defined as the partial derivatives of $\chi_{k}$ with respect to parameters $\sigma_{0}$ and $\Lambda$, respectively, calculated around the reference values $\sigma_{0}^{r e f}$ and $\Lambda^{r e f}$. Then, the variation in the growth rate of unstable modes $\delta \chi_{k}$ due to variations in the parameters $\sigma_{0}$ and $\Lambda$ is estimated as follows:

$$
\begin{aligned}
& \delta \chi_{k} \approx \delta \sigma_{0} \times\left. S_{\sigma}\right|_{\sigma_{0=}=\sigma_{0}^{r e f}} \\
& \delta \chi_{k} \approx \delta \Lambda \times\left. S_{\Lambda}\right|_{\Lambda=\Lambda^{r e f}}
\end{aligned}
$$

where sensitivity functions are defined by

$$
\begin{gathered}
S_{\sigma}=\frac{\chi_{k}}{2 \sigma_{0}}\left[p_{0} \sqrt{\sigma_{0}} \frac{k}{f_{0}} \frac{\eta-2 \operatorname{coth} \eta+2 \eta \operatorname{csch}^{2} \eta}{\eta^{2}-4(\eta \operatorname{coth} \eta-1)}-1\right] \\
S_{\Lambda}=\frac{f_{0}}{2 \sqrt{\sigma_{0}}} \sqrt{\left|\eta^{2}-4(\eta \operatorname{coth} \eta-1)\right|}
\end{gathered}
$$


Considering baroclinic instability on the $\beta$-plane [37] whereby the Coriolis parameter, $f$, is set to vary linearly in the $y$-direction, we derived the following expression for the growth rate of unstable waves (see Equation (A35) in the Appendix A.3):

$$
\chi_{k}=\frac{\sqrt{\left|\beta^{2} \mu^{4}+u_{T}^{2} k^{4}\left(k^{4}-4 \mu^{4}\right)\right|}}{k\left(k^{2}+2 \mu^{2}\right)}
$$

Here $\mu^{2}=f_{0}^{2} /\left[\sigma_{0}(\Delta p)^{2}\right]$ and $u_{T}=\left(u_{1}-u_{2}\right) / 2$, where $u_{1}$ and $u_{2}$ are the wind speeds at $250 \mathrm{hPa}$ and $750 \mathrm{hPa}$ pressure levels respectively.

Differentiating the above equation with respect to parameters, $\sigma_{0}$ and $u_{T}$, we find the sensitivity functions which characterize the influence of static stability and MTG on the growth rate of baroclinic unstable waves:

$$
\begin{gathered}
S_{\sigma}=-\frac{k \mu^{2}}{\sigma_{0}\left(k^{2}+2 \mu^{2}\right)^{2}} \frac{2 u_{T}^{2} k^{4}\left(k^{4}+2 \mu^{2}\right)-\beta^{2} \mu^{2}}{u_{T}^{2} k^{4}\left(k^{4}-4 \mu^{4}\right)+\beta^{2} \mu^{4}} \sqrt{u_{T}^{2} k^{4}\left(k^{4}-4 \mu^{4}\right)+\beta^{2} \mu^{4}} \\
S_{u_{T}}=-u_{T} k^{3}\left(k^{2}-2 \mu^{2}\right) \frac{\sqrt{\left|\beta^{2} \mu^{4}+u_{T}^{2} k^{4}\left(k^{4}-4 \mu^{4}\right)\right|}}{\beta^{2} \mu^{4}+u_{T}^{2} k^{4}\left(k^{4}-4 \mu^{4}\right)}
\end{gathered}
$$

The variation in the growth rate of unstable modes $\delta \chi_{k}$ due to variations in the parameter $u_{T}$ is estimated by the following sensitivity function:

$$
\delta \chi_{k} \approx \delta u_{T} \times\left. S_{u_{T}}\right|_{u_{T}=u_{T}^{r e f}}
$$

In addition to the absolute sensitivity functions, $S_{\alpha}\left(\alpha=\sigma, \Lambda, u_{T}\right)$, relative sensitivity functions, $S_{\alpha}^{R}$, are used to estimate the relative influence of the model parameters on the growth rate of unstable waves, which allow ranking the parameters by the degree of influence of their variations on the variations on the growth rate. Relative sensitivity function is defined by [80]

$$
S_{\alpha}^{R}=\left.\frac{\alpha_{0}}{\chi_{k}} \frac{\partial \chi_{k}}{\partial \alpha}\right|_{\alpha=\alpha_{0}}=\frac{\alpha_{0}}{\chi_{k}} S_{\alpha}
$$

where $\alpha_{0}$ is a certain reference value of the parameter $\alpha$.

\section{Results}

\subsection{Qualitative Analysis}

Extratropical transient cyclonic eddies are wave phenomena, which are formed and evolved in response of the baroclinic instability of atmospheric quasi-zonal westerly flows drawing energy from the MAPE that arises from the MTG. As shown in the previous section, the meridional moisture flux depends on the wavelength of unstable wave which characterizes the size of cyclones. Numerous studies (e.g., [27-34,81,82]) suggest that over the past few decades the length-scale, frequency, and intensity of extratropical cyclones have changed, and a poleward shift of storm tracks and eddy driven jet streams have been observed. Apart from that, the projected changes in the climate system will, to a certain extent, affect the genesis and development of large-scale eddies in the mid-latitude atmosphere [83]. The impact of global warming on the horizontal sizes of transient eddies and their activity (the number of cyclones generated annually) can be qualitatively examined using a simplified theoretical framework 
(e.g., [84]). In a baroclinic atmosphere, the characteristic horizontal length scale of eddies is determined by the first internal Rossby radius of deformation $L_{R}$ [21]:

$$
L_{R}=\frac{N H}{f}=\frac{1}{f} \sqrt{\frac{T}{g}\left(\Gamma_{d}-\Gamma\right)}
$$

where $H$ is the height of homogeneous atmosphere. In the mid-latitudes, typical values for $H, N$, and $f$ are respectively $8 \mathrm{~km}, 10^{-2} \mathrm{~s}^{-1}$, and $1.1 \times 10^{-4} \mathrm{~s}^{-1}$ [21], consequently $L_{R} \approx 850 \mathrm{~km}$.

The impact of global warming on $L_{R}$ can be estimated by the sensitivity coefficient $d L_{R} / d T$. Using logarithmic differentiation to differentiate both sides of Equation (20) with respect to $T$, we obtain

$$
\frac{1}{L_{R}} \frac{d L_{R}}{d T}=\frac{1}{2}\left[\frac{1}{T}-\frac{d \Gamma}{d T}\left(\Gamma_{d}-\Gamma\right)^{-1}\right]
$$

Equation (21) shows that in baroclinic atmosphere the influence of temperature growth on $L_{R}$ is not so clear. The dry adiabatic lapse rate $\Gamma_{d}$ is a constant $9.8^{\circ} \mathrm{C} \mathrm{km}^{-1}$, while the typical value for $\Gamma$ is about $6.5^{\circ} \mathrm{C} \mathrm{km}^{-1}$. Since $\Gamma_{d}>\Gamma$ and $1 / T$ are small, depending on the behavior of $\Gamma$ under global warming, there could be two possible contrasting scenarios, $d L_{R} / d T>0$ and $d L_{R} / d T<0$. Therefore, in order to get a more clear picture of the global warming impact on $L_{R}$, it is useful to explore these two scenarios. To begin, let us consider partial sensitivity coefficients:

$$
\begin{gathered}
\frac{1}{L_{R}} \frac{\partial L_{R}}{\partial T}=\frac{1}{2 T} \\
\frac{1}{L_{R}} \frac{\partial L_{R}}{\partial \Gamma}=-\frac{1}{2\left(\Gamma_{d}-\Gamma\right)}
\end{gathered}
$$

From Equation (22), it follows that a small change $\Delta T$ in temperature causes a fractional change $\Delta L_{R} / L_{R}$ in Rossby radius of deformation of

$$
\frac{\Delta L_{R}}{L_{R}} \approx \frac{1}{2 T} \Delta T
$$

Taking the annual global mean surface temperature $T_{s f c} \approx 288 \mathrm{~K}$ as a reference temperature, we find that $\left(1 / L_{R}\right)\left(\partial L_{R} / \partial T\right)$ is about $0.002 \mathrm{~K}^{-1}$ which means that to increase the temperature by $1 \mathrm{~K}$ leads only to the $0.2 \%$ increase in characteristic length of large-scale eddies. Similarly, we can estimate the effect of small changes in the temperature lapse rate $\Delta \Gamma$ on a fractional change $\Delta L_{R} / L_{R}$ :

$$
\frac{\Delta L_{R}}{L_{R}} \approx-\frac{1}{2\left(\Gamma_{d}-\Gamma\right)} \Delta \Gamma
$$

The characteristic value of $\Gamma$ in the mid-latitude troposphere is $6.5 \mathrm{~K} / \mathrm{km}$, hence the partial sensitivity $\left(1 / L_{R}\right)\left(\partial L_{R} / \partial \Gamma\right)$ is about $-0.15 \mathrm{kmK}^{-1}$, meaning that to increase the lapse rate by $1 \mathrm{~K} / \mathrm{km}$ (i.e., reducing the atmospheric static stability) results in the $15 \%$ decrease in characteristic length of large-scale eddies.

Estimating the total sensitivity coefficient $\left(1 / L_{R}\right)\left(d L_{R} / d T\right)$ using Equation (20) is not a trivial task since this requires a priori knowledge of interdependence between the temperature increase and the lapse rate change. It should be added that to take into consideration the effects of atmospheric moisture on sensitivity coefficients (21) and (23), instead of dry adiabatic lapse rate $\Gamma_{d}$ we would have to use the "effective" lapse rate defined by $\Gamma_{e}=\Gamma_{d}-\left(\Gamma_{d}-\Gamma_{m}\right) \delta_{\text {cloud }}$, where $\Gamma_{m}$ is the moist adiabatic lapse rate and $\delta_{\text {cloud }}$ is a cloud fraction. However, the sensitivity coefficient (21) can be estimated by using observations and/or results of climate modeling. For example, for mid-latitudes, the estimates of the total and partial sensitivity coefficients (21)-(23) were obtained in [84] from NCEP/NCAR reanalysis data and from climate modeling. The estimate of $\left(1 / L_{R}\right)\left(d L_{R} / d T\right)$ is about $-0.0016( \pm 0.0096) \mathrm{K}^{-1}$ from 
the reanalysis data, and $-0.0013 \mathrm{~K}^{-1}$ and $-0.021 \mathrm{~K}^{-1}$ from the results of simulations for dry and moist atmosphere respectively. The estimate of partial sensitivity coefficient $\left(1 / L_{R}\right)\left(\partial L_{R} / \partial T\right)$ is about 0.009 $( \pm 0.007) \mathrm{K}^{-1}$ from the reanalysis data and $0.002 \mathrm{~K}^{-1}$ from the modeling results. In turn, the estimate of partial sensitivity coefficient $\left(1 / L_{R}\right)\left(\partial L_{R} / \partial \Gamma\right)$ is $-0.309( \pm 0.062) \mathrm{km} \mathrm{K}^{-1}$ from the reanalysis data, and $-0.132 \mathrm{kmK}^{-1}$ and $-0.270 \mathrm{kmK}^{-1}$ from the outcomes of simulations for dry and moist atmosphere respectively. Thus, the atmospheric vertical stratification (the lapse rate $\Gamma$ ), which changes with global warming, and atmospheric moisture can affect the horizontal length of baroclinic extratropical transient eddies, leading in aggregate to a decrease in $L_{R}$. However, this decrease is insignificant. For example, results of numerical modeling show that the climate change leads only to the $2 \%$ decrease in characteristic length of large-scale eddies $[84,85]$. We should note that it is not possible to compare sensitivity functions $\left(1 / L_{R}\right)\left(\partial L_{R} / \partial T\right)$ and $\left(1 / L_{R}\right)\left(\partial L_{R} / \partial \Gamma\right)$ as they are sensitivities with respect to different quantities and thus have different dimensions and equivalence classes.

For reference purpose, we also consider the influence of global warming on cyclones' frequency of occurrence using the sensitivity coefficient $(1 / n)(d n / d T)$, where $n$ is the annual mean number of extratropical cyclones in the northern (or southern) hemisphere [86]:

$$
\frac{1}{n} \frac{d n}{d T} \cong-\frac{3}{2 T}+\frac{1}{\Delta T_{p}^{e}} \frac{d \Delta T_{p}^{e}}{d T}-\frac{1}{2\left(\Gamma_{e}-\Gamma\right)} \frac{d\left(\Gamma_{e}-\Gamma\right)}{d T}
$$

where $\Delta T_{p}^{e}$ is the surface temperature differences between the pole and the equator. First, we consider the partial sensitivity coefficients which reflect the sensitivity of $n$ with respect to $T, \Delta T_{p}^{e}$ and $\Gamma$ :

$$
\begin{gathered}
\frac{1}{n} \frac{\partial n}{\partial T} \cong-\frac{3}{2 T} \\
\frac{1}{n} \frac{\partial n}{\partial \Delta T_{p}^{e}} \cong \frac{1}{\Delta T_{p}^{e}} \\
\frac{1}{n} \frac{\partial n}{\partial \Gamma} \cong \frac{1}{2\left(\Gamma_{e}-\Gamma\right)}
\end{gathered}
$$

Substituting the characteristic values for variables $\left(T=288 \mathrm{~K}, \Delta T_{p}^{e}=45^{\circ} \mathrm{C}\right.$; and $\left.\Gamma=6.5 \mathrm{~K} / \mathrm{km}\right)$ into Equations (27)-(29) results in $(1 / n)(\partial n / \partial T) \approx-0.0052 \mathrm{~K}^{-1},(1 / n)\left(\partial n / \partial \Delta T_{p}^{e}\right) \approx-0.022 \mathrm{~K}^{-1}$; while for $(1 / n)(\partial n / \partial \Gamma) \approx-0.152 \mathrm{kmK}^{-1}$. For mid-latitudes, the estimate of total sensitivity coefficient $(1 / n)(d n / d T)$ is about $-0.027( \pm 0.012) \mathrm{K}^{-1}$ from NCEP/NCAR reanalysis data, and $-0.047 \mathrm{~K}^{-1}$ and $-0.029 \mathrm{~K}^{-1}$ from the results of simulations for dry and moist atmosphere respectively [86]. Thus, the effect of global warming on the annual mean number of large-scale eddies generated in the extratropics is of little significance. Clearly, the relationship between climate change and the characteristics of extratropical large-scale eddies is a complex one, with much still to learn. Therefore, estimates obtained are more qualitative in nature since they have a certain degree of uncertainty.

\subsection{Influence of Climate Change on the Grouth Rate of Unstable Waves}

\subsubsection{Growth Rate of Unstable Baroclinic Waves}

It is expected that the static stability of the atmosphere and the temperature difference between the poles and equator will change under climate change. In mid-latitudes, changes in static stability and MTG will affect the development of baroclinic instability and, therefore, the atmospheric eddy meridional heat and moisture transport. In both models ( $f$-plane and $\beta$-plane), the growth rate $\chi_{k}$ of unstable baroclinic waves can be considered as the main characteristic of the development of baroclinic instability [21]. In these two models, the growth rate $\chi_{k}$ is a function of two control parameters: static stability parameter $\sigma_{0}$ and MTG. In the $f$-plane model, the MTG is expressed via the vertical wind shear $\Lambda$ since the thermal wind equation (A7) relates $\Lambda$ to MTG. In the $\beta$-plane model, the thermal wind $u_{T}$ 
serves as a characteristic of MTG. By varying parameters $\sigma_{0}, \Lambda$, and $u_{T}$, we can estimate the climate change impact on $\chi_{k}$ using sensitivity functions $S_{\sigma}, S_{\Lambda}$, and $S_{u_{T}}$ defined by Equations (13), (14), (16), and (17). These functions should be calculated around some reference values of static stability parameter and MTG $\left(\sigma_{0}, \Lambda\right.$ and $\left.u_{T}\right)$, each pair of which corresponds to certain climate conditions (previous, current or future). For the current climate conditions, the reference values of static stability parameter and the vertical wind shear are taken to be $\sigma_{0}^{*}=2 \cdot 10^{-6} \mathrm{~m}^{2} \mathrm{~Pa}^{-2} \mathrm{~s}^{-2}$ and $\Lambda^{\text {ref }}=30 \mathrm{~ms}^{-1} \mathrm{bar}^{-1}$ [21]. The value of $\Lambda^{r e f}=\mathrm{ms}^{-1} \mathrm{bar}^{-1}$ corresponds to $u_{T}=7.5 \mathrm{~ms}^{-1}$, which is used in the $\beta$-plane model and serves as a characteristic of MTG. The reference temperature lapse rate is of $6.5^{\circ} \mathrm{C} \mathrm{km}^{-1}$ which corresponds to $\sigma_{0}^{r e f}=2 \cdot 10^{-6} \mathrm{~m}^{2} \mathrm{~Pa}^{-2} \mathrm{~s}^{-2}$. To take into consideration the influence of atmospheric moisture on the development of baroclinic instability, the effective static stability parameter $\sigma_{0, e f f}^{r e f}$ was also calculated [45]: $\sigma_{0, e f f}^{\text {ref }}=1.16 \cdot 10^{-6} \mathrm{~m}^{2} \mathrm{~Pa}^{-2} \mathrm{~s}^{-2}$. The latitude of interest is assumed to be $\varphi_{0}=45 \mathrm{~N}$ which gives $f_{0} \approx 10^{-4} \mathrm{~s}^{-1}$ and $\beta=1.63 \cdot 10^{-11} \mathrm{~m}^{-1} \mathrm{~s}^{-1}$.

The growth rate of the unstable waves as a function of zonal wavenumber $k_{z}$ for the "dry" and "moist" $f$-plane and $\beta$-plane models are illustrated in Figure 1 . The $f$-plane model has a short-wave cutoff. In other words, there is a critical value of wavelength $L_{\min }^{f}$ above which instability occurs. If wavelength $L_{w}<L_{\min }^{f}$ then the phase velocity is purely real and, therefore, this wave is stable, and its amplitude does not grow with time [36]. The value of $L_{\min }^{f}$ is obtained from the condition that the discriminant $\eta^{2}-4(\eta \operatorname{coth} \eta-1)$ of the Equation (10) is equal to zero, which gives $\eta=\eta_{c}=2.3994$ and, therefore, $L_{\text {min }}^{f} \approx 3575 \mathrm{~km}$ for the "dry" model, and $L_{\text {min }}^{f} \approx 2735 \mathrm{~km}$ for the "moist" model (see Table 1). Thus, under the influence of the atmospheric moisture, baroclinic unstable waves are shifted into the shortwave part of the spectrum.

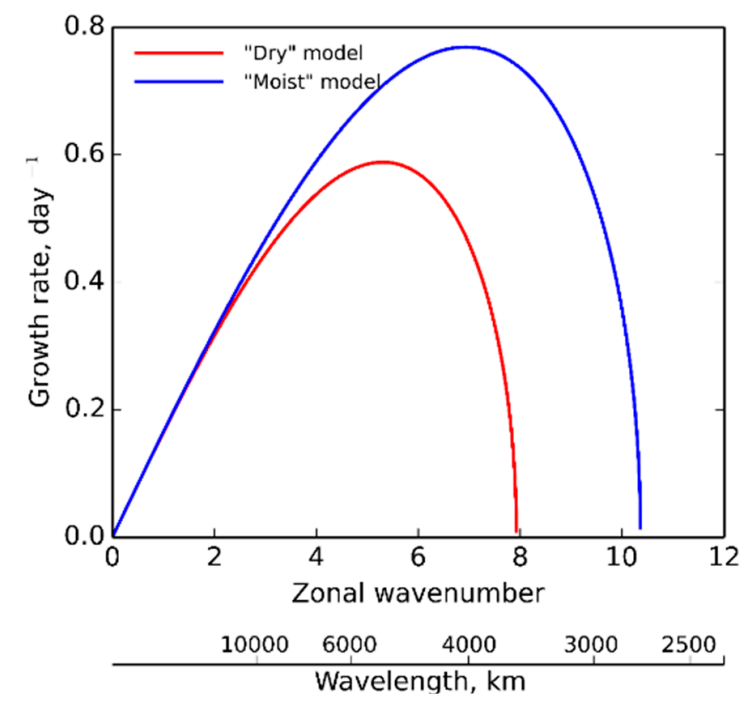

(a)

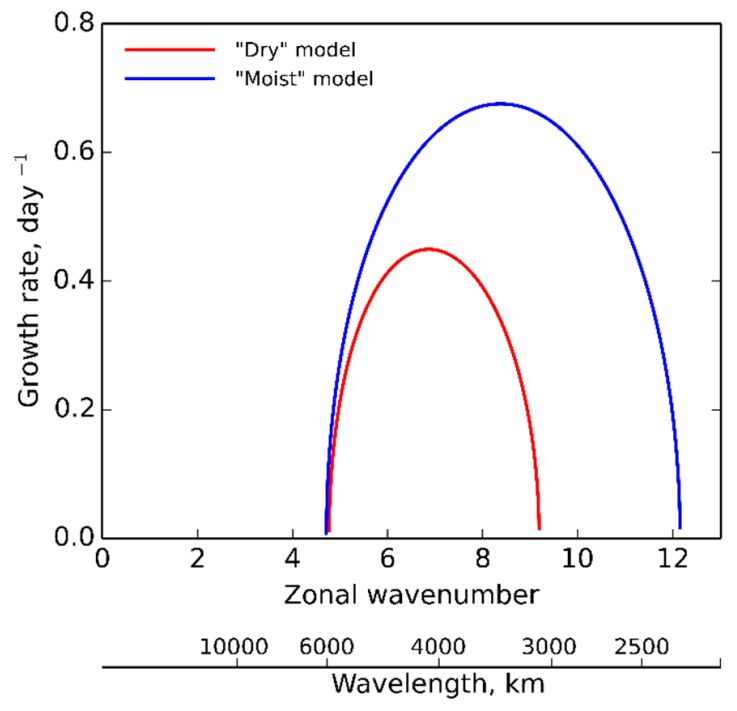

(b)

Figure 1. Growth rate $\chi_{k}=k c_{i}$ as a function of zonal wavenumber $k_{z}$ for the "dry" and "moist" (a) $f$-plane and (b) $\beta$-plane models, as described by Equations (10) and (15) respectively. 
Table 1. Characteristics of baroclinic instability obtained from the $f$-plane and $\beta$-plane models.

\begin{tabular}{cccccc}
\hline Models & $\boldsymbol{L}_{\text {min }^{\prime}}^{f} \mathbf{~ k m}$ & $\boldsymbol{L}_{\text {max }}^{f}, \mathbf{k m}$ & $\boldsymbol{L}_{\mathbf{k c m a x}}^{f}, \mathbf{k m}$ & $\chi_{\boldsymbol{k}}, \mathbf{d a y}^{-1}$ & $\boldsymbol{t}^{d}$, day \\
\hline $\begin{array}{c}f \text {-plane models: } \\
\text { "Dry" }\end{array}$ & 3.575 & - & 5340 & 0.59 & 1.18 \\
"Moist" & 2735 & - & 4090 & 0.77 & 0.90 \\
\hline $\begin{array}{c}\beta \text {-plane models: } \\
\text { "Dry" }\end{array}$ & 3085 & 5945 & 4130 & 0.45 & 1.54 \\
"Moist" & 2333 & 6015 & 3385 & 0.68 & 1.02 \\
\hline \multicolumn{5}{c}{ Note: $t^{d}$ is a doubling time. }
\end{tabular}

Note that one of the disadvantages of $f$-plane model is that the long waves are unstable that contradicts, at least, the results of the numerical simulations with global models, which show that planetary-scale waves are practically stable. It is well-known that this is a consequence of the $f$-plane approximation [21]. In other words, in order to obtain a qualitatively correct result for long waves using simple models, it is needed to consider the $\beta$-effect (see Figure $1 \mathrm{~b}$ ). Examining the $\beta$-plane model, we can plot the marginal stability (neutral) curve that separates stable and unstable waves by setting the discriminant $\beta^{2} \mu^{4}+u_{T}^{2} k^{4}\left(k^{4}-4 \mu^{4}\right)$ of the Equation (15) equal to zero. Then we can find both the shortwave cut-off $L_{\min }^{\beta}$ and the longwave cut-off $L_{\text {max }}^{\beta}$. Thus, unstable waves satisfy the condition $L_{\min }^{\beta} \leq L_{w} \leq L_{\max }^{\beta}$. The values of $L_{\min }^{\beta}$ for the "dry" and "moist" models are, respectively, 3085 and $2333 \mathrm{~km}$, whereas the values of $L_{\max }^{\beta}$ for the "dry" and "moist" models are of 5945 and $6015 \mathrm{~km}$ respectively (see Table 1).

The influence of static stability and MTG on the growth rate of baroclinic unstable waves is usually analyzed with respect to the most unstable wave, since this wave will dominate the evolutionary process of baroclinic instability [21]. The wavelength $L_{k c m a x}$ of the most unstable wave corresponds to the point at which $\partial \chi_{k} / \partial k=0$. For the "dry" and "moist" versions of $f$-plane model the values of $L_{k c \text { max }}^{f}$ are, respectively, 5340 and $4090 \mathrm{~km}$, whereas for the $\beta$-plane model -4130 and $3385 \mathrm{~km}$ respectively. The calculated values of $L_{k c m a x}$ for the "moist" versions of both the $f$-plane and $\beta$-plane models agreeing well with the observed extratropical cyclonic waves. In this regard a few clarifications are required. The two models used in this study fundamentally describe the formation of cyclones in the entire thickness of the troposphere, which is almost impossible since loss of stability usually occurs in the lower troposphere. Numerical experiments with multilayer general circulation models of the atmosphere show that the maximum growth rate of unstable modes shifts toward higher wavenumbers with $k=14,15\left(L_{w} \approx 2000 \mathrm{~km}\right)$ [87]. Since the vertical profile of these modes has a maximum in the lower troposphere, when calculating their growth rates it is necessary to take into account the energy dissipation in the atmospheric boundary layer and the turbulent dissipation due to the horizontal wind shear, which is proportional to the squared wavenumber (e.g., $[47,87])$. When this dissipation is taken into account in general circulation models, then the maximum of the resulting growth rate shifts again to the spectral region with wave numbers $k=6-8\left(L_{w} \approx 3500-4500 \mathrm{~km}\right)$ [87].

\subsubsection{Sensitivity Functions}

Sensitivity functions $S_{\sigma}$ with respect to the static stability parameter as functions of zonal wavenumber $k_{z}$ for the "dry" and "moist" $f$-plane and $\beta$-plane models are plotted in Figure 2 . As the wavenumber increases, the absolute values of sensitivity functions $S_{\sigma}$ grow exponentially meaning that the effect due to a change in the vertical stratification of the atmosphere substantially depends on the unstable wavelength. Short waves are more affected by changes in atmospheric static stability than longer waves. Atmospheric moisture also noticeably affects the sensitivity of unstable waves to the parameter of static stability (see Table 2). Results show that the $\beta$-plane model is more sensitive to the static stability then the $f$-plane model. Since sensitivity functions $S_{\sigma}$ obtained from $f$-plane and $\beta$-plane 
models are negative for all unstable waves, the increase in static stability leads to the decrease in the growth rates of unstable modes.

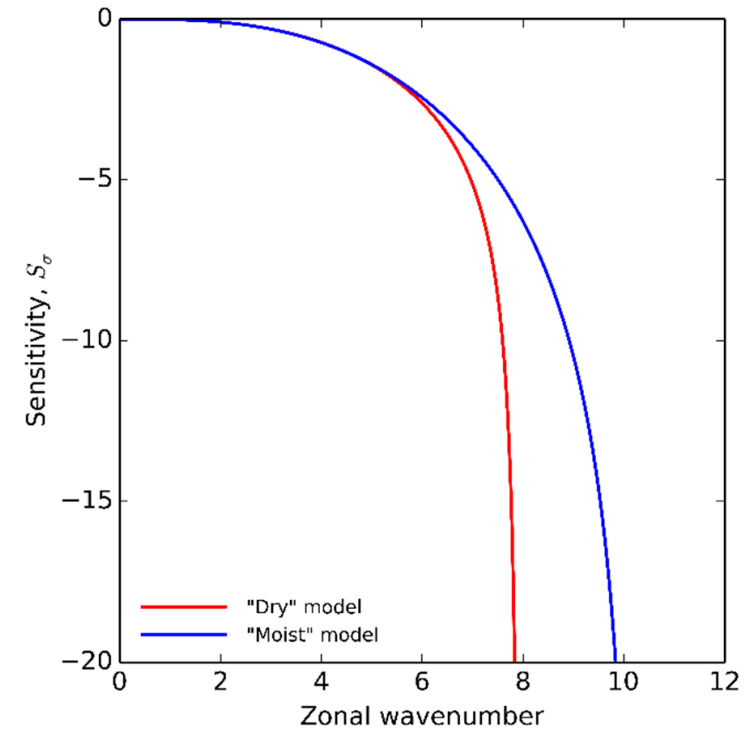

(a)

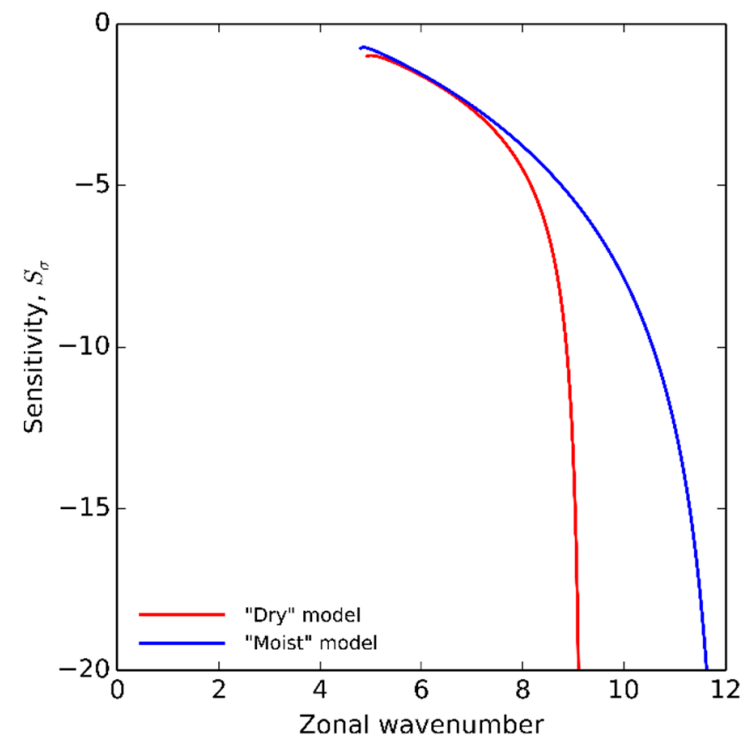

(b)

Figure 2. Sensitivity functions $S_{\sigma}$ with respect to the static stability parameter as functions of the zonal wavenumber $k_{z}$ for the "dry" and "moist" (a) $f$-plane and (b) $\beta$-plane models.

Table 2. Absolute and relative sensitivity functions for the most unstable wave obtained from the $f$-plane and $\beta$-plane models.

\begin{tabular}{cccccc}
\hline Models & $S_{\sigma}$ & $S_{\Lambda}$ & $S_{u_{T}}$ & $S_{\sigma}^{R}$ & $S_{u_{T}}^{R}$ \\
\hline $\begin{array}{c}f \text {-plane models: } \\
\text { "Dry" }\end{array}$ & -1.71 & 0.0196 & - & -0.50 & - \\
"Moist" & -3.84 & 0.0256 & - & -0.50 & - \\
\hline$\beta$-plane models: & & & & & \\
"Dry" & -2.47 & - & 0.0864 & -0.94 & 1.44 \\
"Moist" & -4.34 & - & 0.1031 & -0.64 & 1.14 \\
\hline
\end{tabular}

Note: $S_{\Lambda}^{R}=1$ for all unstable waves.

Sensitivity functions $S_{\Lambda}$ and $S_{u_{T}}$ which represent the influence of MTG on the growth rate of unstable waves for the "dry" and "moist" $f$-plane and $\beta$-plane models are shown in Figure 3 . From the comparison of graphs shown in Figures 1a and 3a, it follows that the graph of function $S_{\Lambda}$ is similar to the graph of function $\chi_{k}$. Therefore, in the $f$-plane model, the most unstable wave possesses the highest sensitivity to MTG, while in the $\beta$-plane model, the shorter the wave, the more sensitive it is to the horizontal temperature gradient, which is consistent with the results obtained from general circulation models of the atmosphere (e.g., $[47,87])$. It can be shown that the sensitivity functions $S_{\Lambda}$ and $S_{u_{T}}$, when considered over the same domain of wavenumbers, are related by the equation $S_{\Lambda}=0.25 \times S_{u_{T}}$. Using this equation, we can compare the results obtained from both models. 


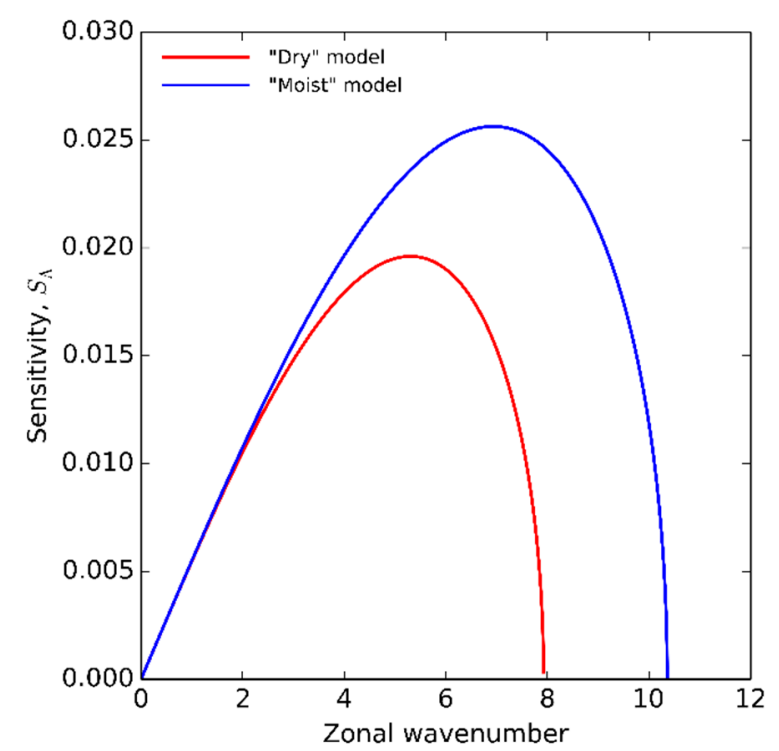

(a)

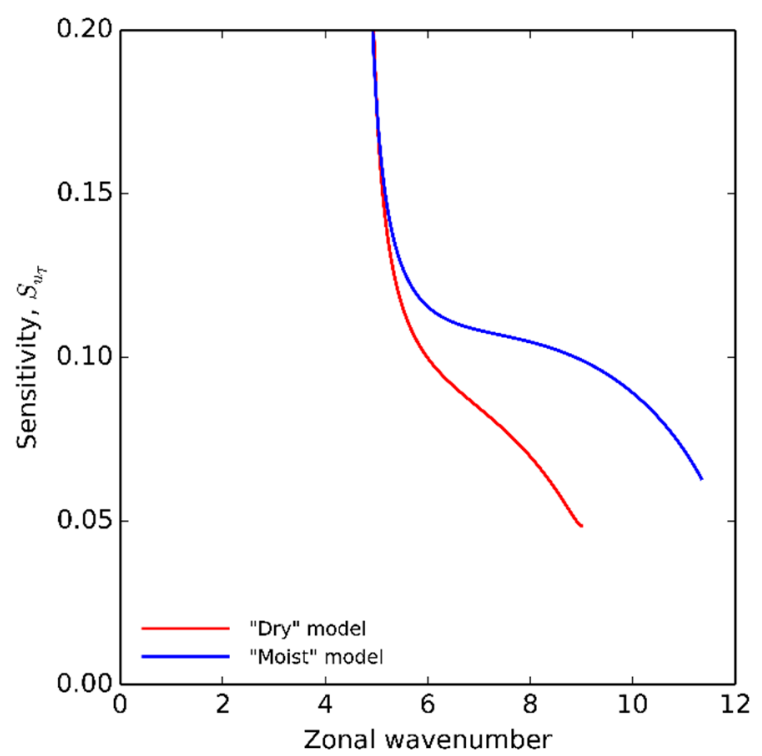

(b)

Figure 3. Sensitivity functions with respect to the meridional temperature gradient (MTG) parameter versus zonal wavenumbers for the "dry" and "moist" (a) $f$-plane and (b) $\beta$-plane models.

The relative importance of control parameters, the static stability parameter and MTG, in the development of baroclinic instability can be estimated using relative sensitivity functions displayed in Figure 4 . The analysis of relative sensitivity functions shows that for each model "dry" and "moist" $f$-plane and $\beta$-plane) there is a critical wavelength $L_{c}$ that splits up the wave spectrum in two regions. In the development of baroclinic instability the static stability plays more important role than the MTG for waves with $L_{w}<L_{c}$. In contrast, for waves with $L_{w}>L_{c}$ the MTG are more important than the static stability. Atmospheric moisture strongly affects the critical value $L_{c}$. For the "dry" ("moist") $f$-plane model the critical wavelength is $4500(3500) \mathrm{km}$, whereas for the $\beta$-plane model $-3800(2900) \mathrm{km}$.

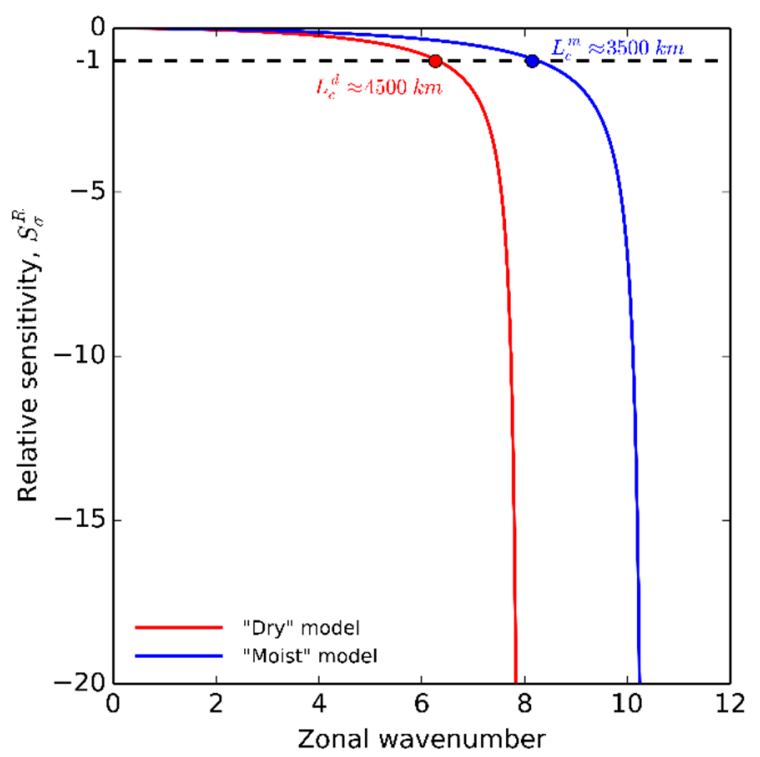

(a)

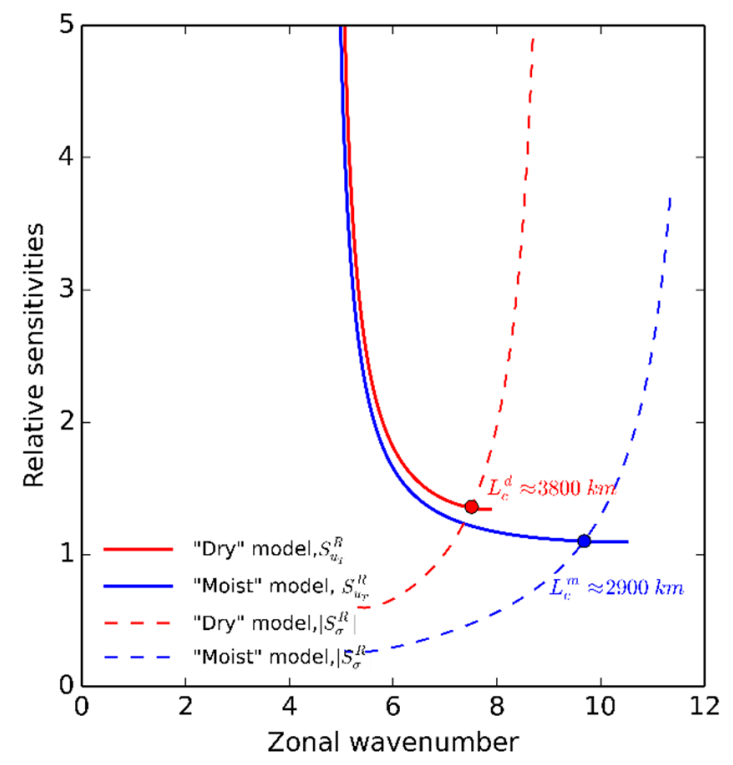

(b)

Figure 4. Relative sensitivity functions versus zonal wavenumbers for the "dry" and "moist" (a) $f$-plane and (b) $\beta$-plane models. 


\subsubsection{Estimating Climate Change Impact on Eddy Meridional Moisture Transport}

The Effect of Static Stability on Eddy Meridional Moisture Transport

In order to estimate the effect of static stability on eddy meridional moisture transport, we need to define a climate change scenario that includes estimates of both surface and upper tropospheric temperature changes. Surface temperature change is a well-studied phenomenon and thus we will use the estimate provided in the WMO report [2], according to which the average surface temperature has increased by roughly $1{ }^{\circ} \mathrm{C}$ over the last century. Temperature change in upper troposphere is significantly more uncertain given the fact that various measurement techniques (e.g., radiosondes, satellites) produce inconsistent results. For the purposes of this study, we will make use of an estimate provided in [60], which found that the increase in upper tropospheric temperature outpaces the increase in surface temperature by about $2{ }^{\circ} \mathrm{C}$ in mid-latitudes. In this scenario, the temperature lapse rate $\Gamma=-d T / d z$ has decreased from the initial (base) value of $6.5^{\circ} \mathrm{C} / \mathrm{km}$ to $6.3^{\circ} \mathrm{C} / \mathrm{km}$. This change leads to the following dynamical effects: the temperature in the middle troposphere increases by about $1.8^{\circ} \mathrm{C}$, the dry static stability parameter also increases slightly (by about $0.7 \%$ ). However, the effective static stability parameter $\Gamma_{\text {eff }}$ actually demonstrates the opposite behavior: $\Gamma_{e f f}$ decreases by more than $5.4 \%$. Thus, dry and moist models provide completely distinct results both quantitatively and qualitatively. The growth rate $k c_{i}$ of the most unstable mode obtained using the dry $f$-plane model decreases slightly, by about $0.2 \times 10^{-2}$ day $^{-1}$, which is $0.36 \%$ of the base value shown in Table 1 . On the other hand, the moist $f$-plane model shows an increase in the growth rate $k c_{i}$ of $\sim 2.2 \times 10^{-2}$ day $^{-1}$, which is $\sim 2.8 \%$ of the base value (see Table 1 ). In dry $\beta$-plane model, the growth rate of the most unstable wave decreases by about $0.3 \times 10^{-2}$ day $^{-1}$, which is $0.7 \%$ of the base value shown in Table 1 , while in the moist version of this model the growth rate increases by more than $2.4 \times 10^{-2}$ day $^{-1}$, which is $\sim 3.6 \%$ of the base value. Changes in the growth rates of unstable waves cause changes in AMEMF. This effect can be estimated from the Equation (9). For the dry $f$-plane and $\beta$-plane models, the decrease in AMEMF is insignificant, only about $0.5 \%$ for both models, while in the moist $f$-plane and $\beta$-plane models there is an increase in AMEMF by about $4.5 \%$ and more than $5 \%$, respectively. Hence the results obtained with $f$-plane and $\beta$-plane models are quite similar.

\section{The Effect of Meridional Temperature Gradient on Eddy Meridional Moisture Transport}

Let us now consider the effect of changes due to the global warming in the second control parameter, MTG, on the growth rate of unstable baroclinic waves and, consequently, on the AMEMF. The thermal wind equation relates MTG to the vertical wind shear, which in $f$-plane and $\beta$-plane models is characterized by parameters $\Lambda$ and $u_{T}$, respectively. In general, the larger the equator-to-pole temperature difference, the stronger the resulting wind shear will be. If we know the MTG variation caused by climate change, then we can find the corresponding changes in the parameters $\Lambda$ and $u_{T}$ by solving the thermal wind equation. In the next step, after the variations $\delta \Lambda$ and $\delta u_{T}$ have been calculated, we can analytically estimate their influence and, therefore, the effect of MTG variations on the change in the growth rates of unstable modes by using Equations (14) and (17) and taking into account the known values of sensitivity functions $S_{\Lambda}$ and $S_{u_{T}}$ (see Table 2). However, we first need to determine the variation in MTG caused by the climate change.

It has previously been shown that in polar areas changes in surface air temperature $T_{s f c}$ caused by a change in the planetary energy balance are greater than changes in $T_{s f c}$ in the mid-latitude and equatorial areas. Known as polar amplification, this climatic phenomenon is more profound in the northern hemisphere than in the southern hemisphere [88,89].

The earth's energy imbalance can be caused by various natural and human factors and, in particular, by changes in the concentrations of anthropogenic greenhouse gases in the atmosphere [90,91]. As a specific example, we consider the northern hemisphere. Because of Arctic amplification, the surface air temperature at high latitudes of the northern hemisphere increased at about twice the rate of global mean surface temperature since the middle of the 20th century [92]. Arctic amplification is traced 
near the surface and in the lower troposphere, weakening MTG and, thus, reducing the vertical wind shear and contributing to the weakening of the westerly mid-latitude jet stream. In the upper and middle troposphere, however, climate change enhances MTG, thereby increasing the vertical wind shear and contributing to strengthening the zonal flow [93-96]. Exploration of historic trends in the upper-tropospheric vertical wind shear in the North Atlantic region based on three independently created reanalysis datasets has shown that in the area of interest the vertical wind shear has increased by about $15 \%$ over the last few decades [94].

As noted in [94], a stronger MTG and a correspondingly stronger vertical wind shear in the upper troposphere are masked by a weaker MTG and a correspondingly weaker vertical wind shear in the lower troposphere. Climate modeling results show that changes in the upper-tropospheric MTG play a primary role in the formation of large-scale atmospheric dynamics at mid-latitudes, affecting the intensity of vertical wind shear and zonal flow, while changes in the lower tropospheric MTG play a secondary role [97,98]. The annual-mean equator-to-pole temperature difference over the troposphere is about $40{ }^{\circ} \mathrm{C}$, so the average tropospheric MTG is about $4{ }^{\circ} \mathrm{C}$ per $1000 \mathrm{~km}$ [99]. However, MTG varies with latitude. The strongest MTG is concentrated in the middle latitudes, contributing to the formation of the so-called upper tropospheric frontal zone and the associated zonal flow, the speed of which increases with height $[20,99]$. In this study, we have assumed that the vertical wind shear parameter $\Lambda$ used in $f$-plane model is $30 \mathrm{~ms}^{-1} \mathrm{bar}^{-1}$ [21,42]. Accordingly, the parameter $u_{T}$ that characterises the vertical wind shear in $\beta$-plane model is $7.5 \mathrm{~ms}^{-1}$. This vertical wind shear is associated with an upper-tropospheric frontal zone which in our case extends over the entire thickness of the troposphere and has an MTG of $\sim 7.54^{\circ} \mathrm{C}$ per $1000 \mathrm{~km}$. Note that in well-developed upper-tropospheric frontal zones, the temperature contrast can reach $11-12{ }^{\circ} \mathrm{C}$ per $1000 \mathrm{~km}$ in mid-latitudes.

Based on preceding discussion, when determining the MTG value, we assume that climate change weakens the annual MTG in the lower troposphere through more significant heating of higher latitudes, whereas in the upper troposphere MTG increases because of a strong upper-tropospheric warming of lower latitudes. For a climate change scenario discussed in this paper, the response of the mass-weighted vertically averaged annual mean MTG to increase in the surface temperature by $1{ }^{\circ} \mathrm{C}$ is about $-0.2{ }^{\circ} \mathrm{C}$ per $1000 \mathrm{~km}$, which is $\sim 2.7 \%$ of the base value. Accordingly, this change in MTG generates the following variations in the parameters $\Lambda$ and $u_{T}$ that characterize the vertical wind shear: $\delta \Lambda=+0.8 \mathrm{~ms}^{-1} \mathrm{bar}^{-1}$ and $\delta u_{T}=+0.2 \mathrm{~ms}^{-1}$. Next we can estimate the influence of $\delta \Lambda$ and $\delta u_{T}$ on the growth rate of the most unstable mode $k c_{i}$ using Equations (12) and (18). Values for sensitivity functions $S_{\Lambda}$ and $S_{u_{T}}$ used in this equation are shown in Table 2. Calculations show that the growth rate $k c_{i}$ obtained from the dry $f$-plane model increases by $\sim 0.016$ day $^{-1}$. In turn, the growth rate obtained from the moist $f$-plane model increases by $\sim 0.020$ day $^{-1}$, however, in relative terms, this increase is also $2.7 \%$ of the base value since the base growth rate is larger in the moist model than in the dry model. The $\beta$-plane model yields fairly similar results. In the dry version of this model, $k c_{i}$ increases by $\sim 0.017 \mathrm{day}^{-1}$, which is about $4 \%$ of the base value, and in the moist version by $\sim 0.021$ day $^{-1}$, which is $3.1 \%$ of the base value. Now, we can estimate the effect of MTG change on the meridional moisture transport using the Equation (9) and the obtained values of $\Delta\left(k c_{i}\right)$. The AMEMF calculated using dry $f$-plane and $\beta$-plane models increases by $3.2 \%$ and $4.2 \%$, respectively. In turn, increases in the meridional moisture flux obtained from the moist $f$-plane and $\beta$-plane models are $3.5 \%$ and $4.2 \%$ respectively.

\section{Discussion}

In summary, using the two classic atmospheric models, mid-latitude $f$-plane, and $\beta$-plane models, for baroclinic instability we have estimated the climate change impact on the mid-latitude moisture transport. Fundamental dynamical parameters, static stability parameter, and MTG, were used as indicators of climate change, and the static stability parameter was calculated both with and without considering the atmospheric moisture ("moist" and "dry" models respectively). We have shown that neglecting atmospheric moisture in the calculation of static stability parameter (in other words, the use 
of the dry static stability parameter instead of the effective static stability parameter) leads to tangible differences between the results obtained using dry and moist models. Because of the climate change, the dry static stability parameter slightly increases, weakening AMEMF only insignificantly (by less than $0.5 \%$ ). At the same time, the effective static stability parameter decreases causing an intensification of baroclinic instability and, consequently, an increase in AMEMF of about $5 \%$.

In addition to affecting the static stability of the atmosphere, climate change also affects the MTG, which is one of the main fundamental dynamical parameters that "controls" the global atmospheric circulation and the eddy meridional moisture transport. Although the changes in MTG in the lower troposphere and the upper troposphere have opposite signs, the mass-weighted vertically averaged annual-mean MTG increases under global warming. This leads to an enhanced vertical wind shear producing more favorable conditions for the development of baroclinic instability and generation of large-scale atmospheric eddies that transport moisture from low to high latitudes. According to the climate change scenario discussed here, the response of the mass-weighted vertically averaged annual mean MTG to an increase in the surface temperature of $1{ }^{\circ} \mathrm{C}$ is about $-0.2^{\circ} \mathrm{C}$ per $1000 \mathrm{~km}$, which is $\sim 2.7 \%$ of the base value. In turn, under this change in MTG the parameters $\Lambda$ and $u_{T}$, which characterize the vertical wind shear, also increase by $0.8 \mathrm{~ms}^{-1} \mathrm{bar}^{-1}$ and $0.2 \mathrm{~ms}^{-1}$ respectively, thereby strengthening the eddy meridional moisture transport by about $4 \%$.

Suppose that the static stability of the atmosphere and the MTG are independent of each other, or in other words, suppose that these parameters change independently of one other under the influence of climate change. Then, from the moist models (models with effective static stability parameter), it can be estimated that an increase in near-surface temperature by $1{ }^{\circ} \mathrm{C}$ leads to an increase in AMEMF of about $9 \%$ compared with the reference climate state.

However, since the effect of static stability is negligible in dry models, an increase in AMEMF is solely attributable to a change in the MTG. The assumption that the parameters are independent of each other is fairly often used in the sensitivity analysis of systems when considering the influence of infinitesimal parameter variations on model variables. This approach is referred to as "One-factor-at-a-time" (OAT). In our case, the use of this approach is quite reasonable, since we are studying the effects of infinitesimal variations caused by climate change in the static stability parameter and the MTG on the growth rate of unstable baroclinic waves and, hence, on the AMEMF. The sensitivity functions obtained represent an efficient tool for estimating the impact of various climate change scenarios on changes in the AMEMF

In the climate change scenario being considered, the temperature of lower troposphere, in which the atmospheric moisture is concentrated, increases by about $1.5^{\circ} \mathrm{C}$. This leads to an increase in specific humidity of about $10.5 \%$. Thus, since both AMEMF and atmospheric water vapor content increase under this scenario, a rather noticeable restructuring of the global water cycle is expected. For instance, in middle and high latitudes, the meridional moisture transport enhanced due to the global warming may lead to more precipitation overall as well as changes in the intensity and frequency of heavy rainfall events increasing the likelihood of flooding, particularly in coastal areas.

In this study, we applied an idealized framework to estimate the response of AMEMF to changes that occur in the earth's climate system under global warming. Undoubtedly, the results obtained from simplified models should be approached with caution. Ideally, further studies are required to simulate climate change impact on the global hydrological cycle using more complex climate models with full physics and high resolution. However, this problem is quite costly in terms of computational resources, so obtaining estimates using a simplified (classical) framework is very useful for better understanding the fundamentals of thermodynamic effects of climate change.

Funding: This research received no external funding.

Conflicts of Interest: The author declares no conflict of interest. 


\section{Nomenclature}

The following symbols are used consistently throughout the paper. Any additional symbols are defined in the text as they are introduced.

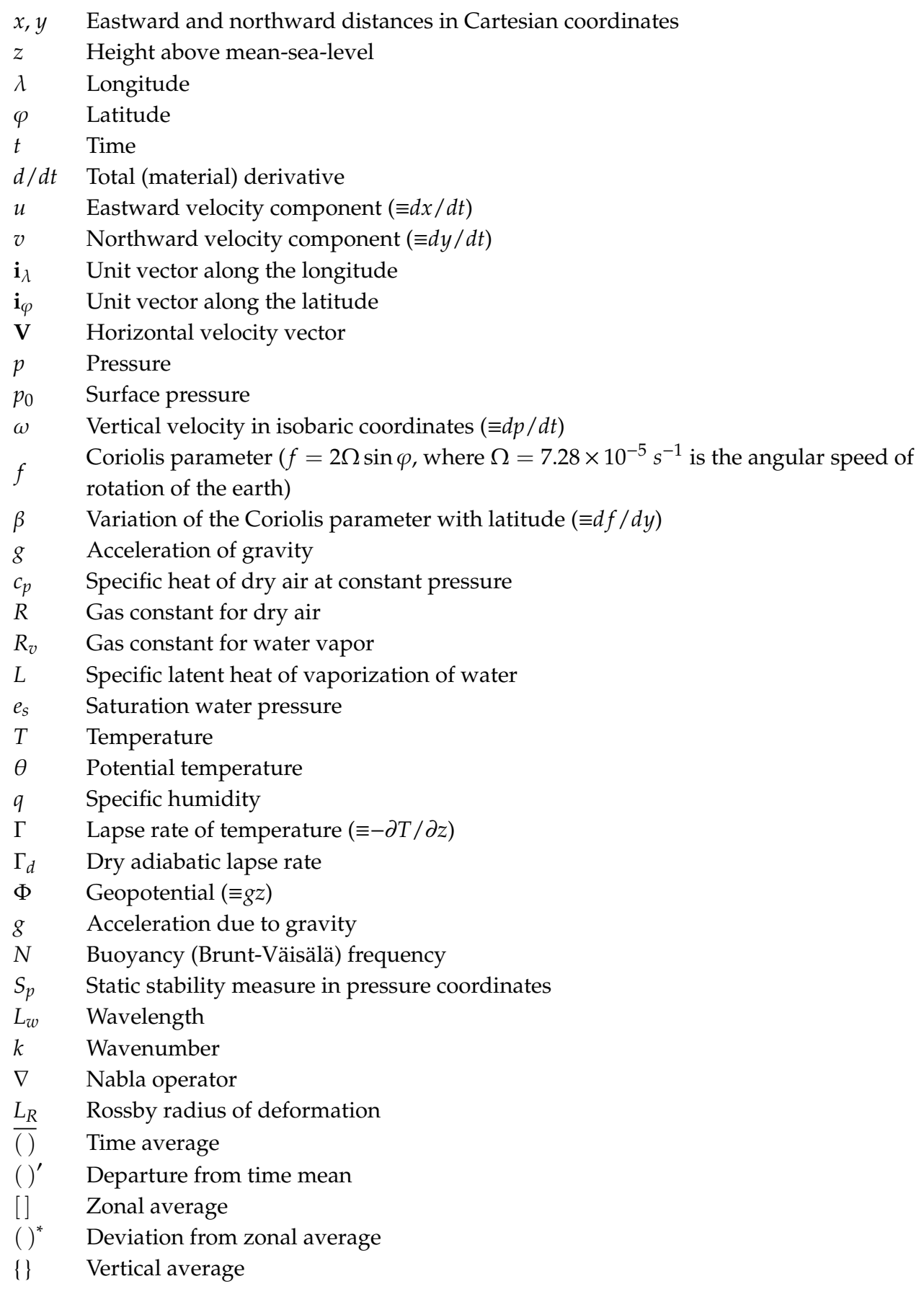

\section{Appendix A}

Appendix A.1. Basic Equation Describing Large-Scale Atmospheric Dynamics

Let us consider the following set of basic equations called the (hydrostatic) primitive equations in pressure coordinates describing the inviscid large-scale atmospheric motions (e.g., [21]): 
(a) The horizontal momentum equations

$$
\begin{aligned}
& \frac{\partial u}{\partial t}+u \frac{\partial u}{\partial x}+v \frac{\partial u}{\partial y}+\omega \frac{\partial u}{\partial p}-f v+\frac{\partial \Phi}{\partial x}=0 \\
& \frac{\partial v}{\partial t}+u \frac{\partial v}{\partial x}+v \frac{\partial v}{\partial y}+\omega \frac{\partial v}{\partial p}+f u+\frac{\partial \Phi}{\partial y}=0
\end{aligned}
$$

(b) The hydrostatic equation

$$
\frac{\partial \Phi}{\partial p}=-\frac{R T}{p}
$$

(c) The continuity equation

$$
\frac{\partial u}{\partial x}+\frac{\partial v}{\partial y}+\frac{\partial \omega}{\partial p}=0
$$

(d) The thermodynamic equation

$$
\frac{\partial T}{\partial t}+u \frac{\partial T}{\partial x}+v \frac{\partial T}{\partial y}-\frac{R T}{g p}\left(\Gamma_{d}-\Gamma\right) \omega=\frac{\dot{Q}}{c_{p}}=0
$$

where $\dot{Q}$ is the diabatic heating rate per unit mass.

Equations (A1)-(A5) possess a steady-state solution

$$
\bar{u}=-f^{-1} \frac{\partial \Phi}{\partial y}, \bar{v}=0, \bar{\omega}=0, \frac{\partial \bar{\Phi}}{\partial p}=-\frac{R \bar{T}}{p},
$$

which describes the zonal flow induced by a meridional (along a longitude circle of the earth) temperature contrast defined by the temperature field $\bar{T}=\bar{T}(y, p)$. A vertical wind shear in this zonal flow is defined by the thermal wind relation

$$
\frac{\partial \bar{u}}{\partial p}=\frac{R}{f p} \frac{\partial \bar{T}}{\partial y}
$$

The boundary conditions will be considered below. The large-scale mid-latitude atmospheric motions are nearly geostrophic, which implies the balance between the Coriolis and horizontal pressure gradient forces. This results in the air moving along isobars, with the low pressure to the left in the northern hemisphere, and the low pressure to the right in the southern hemisphere. It follows from Equations (A1) and (A2) that the geostrophic wind components are given by

$$
u_{g}=-\frac{1}{f} \frac{\partial \Phi}{\partial y}, v_{g}=\frac{1}{f} \frac{\partial \Phi}{\partial x}
$$

\section{Appendix A.2. The f-Plane Model}

In general, the life cycle of baroclinic unstable waves has three main stages: the initial stage, in which unstable waves grow exponentially; the mature stage, in which the waves reach saturation and transform into large-scale eddies (cyclones and anticyclones); and the decay stage, in which eddies dissipate. To explore the initial stage, theoretical models usually employ linearized dynamics equations whereby the instability problem is examined as an eigenvalue problem. To isolate the baroclinic mechanism of instability in pure form, we will exclude from consideration the $y$-dependence of atmospheric zonal flow.

First, we consider the $f$-plane baroclinic instability model [36] in which the Coriolis parameter $f$ is set to a constant value, i.e., $f=f_{0}=2 \Omega \sin \varphi_{0}$, where $\Omega=7.29 \times 10^{-5} \mathrm{~s}^{-1}$ is the angular speed of rotation of the earth and $\varphi_{0}$ is the reference latitude $\left(\varphi_{0} \sim 60^{0} \mathrm{~N}\right)$. Then the eigenvalue problem, with some additional simplifications discussed below, can be solved analytically using the perturbation 
method. This technique requires representing each dependent variable $\psi(x, y, p, t)$ as the sum of a reference (basic) state $\bar{\psi}(p)$ and the infinitesimal (sufficiently small) perturbation $\psi^{\prime}(x, p, t)$ such that $\psi^{\prime} \ll \psi:$

$$
\psi(x, y, p, t)=\bar{\psi}(p)+\psi^{\prime}(x, y, p, t), \psi=(u, v, \omega, T, \Phi)
$$

Substituting the above expression into Equations (A1)-(A5) and neglecting the second-order terms, we obtain the following linear set of differential equations for two-dimensional perturbations:

$$
\begin{gathered}
\frac{\partial u^{\prime}}{\partial t}+\bar{u} \frac{\partial u^{\prime}}{\partial x}+\omega^{\prime} \frac{\partial \bar{u}}{\partial p}-f_{0} v^{\prime}+\frac{\partial \Phi^{\prime}}{\partial x}=0 \\
\frac{\partial v^{\prime}}{\partial t}+\bar{u} \frac{\partial v^{\prime}}{\partial x}+f_{0} u^{\prime}=0 \\
\frac{\partial u^{\prime}}{\partial x}+\frac{\partial \omega^{\prime}}{\partial p}=0 \\
\frac{\partial}{\partial t}\left(\frac{\partial \Phi^{\prime}}{\partial p}\right)+\bar{u} \frac{\partial}{\partial x}\left(\frac{\partial \Phi^{\prime}}{\partial p}\right)-f_{0} v^{\prime} \frac{\partial \bar{u}}{\partial p}+\sigma_{0} \omega^{\prime}=0
\end{gathered}
$$

where $\sigma_{0}$ is the static stability parameter (for simplicity taken constant):

$$
\sigma_{0}=\frac{R^{2} \bar{T}}{g p^{2}}\left(\Gamma_{d}-\Gamma\right)
$$

To define a baroclinic instability problem that results in a unique solution, we must specify boundary conditions for the Equations (A9)-(A12). The linear equations are complemented by periodic boundary conditions in $x$-direction for all model variables, and the rigid lids at the top $(p=0)$ and bottom $\left(p=p_{0}=10^{5} \mathrm{~Pa}\right)$ :

$$
\omega^{\prime}=0 \text { at } p=0 \text { and } p=p_{0}
$$

We will look for plane-wave solutions of the form:

$$
\psi^{\prime}(x, p, t)=\hat{\psi}(p) e^{i k(x-c t)}
$$

where the amplitude of perturbation $\hat{\psi}$ is a function of $p$ only, $k$ is a zonal wavenumber, and $c$ is a complex phase velocity of perturbations. Substituting the assumed solution (A15) into linear Equations (A9)-(A12) we will obtain the set of algebraic equations:

$$
\begin{gathered}
i k(\bar{u}-c) \hat{u}-f_{0} \hat{v}+\hat{\omega} \frac{\partial \bar{u}}{\partial p}=-i k \hat{\Phi} \\
i k(\bar{u}-c) \hat{v}+f_{0} \hat{u}=0 \\
i k \hat{u}+\frac{\partial \hat{\omega}}{\partial p}=0 \\
i k(\bar{u}-c) \frac{\partial \hat{\Phi}}{\partial t}-f_{0} \hat{v} \frac{\partial \bar{u}}{\partial p}+\sigma_{0} \hat{\omega}=0
\end{gathered}
$$

If we assume that the velocity of zonal flow linearly increases with altitude, i.e., $\bar{u}(p)=\Lambda\left(p_{0}-p\right)$, where $\Lambda=-\partial \bar{u} / \partial p$, then we find that the vertical structure of the atmosphere is given by the solution of the second order differential equations for the amplitude of vertical velocity perturbation $\hat{\omega}$ [41]:

$$
(\bar{u}-c)\left[1-\frac{k^{2}}{f_{0}^{2}}(\bar{u}-c)(\bar{u}-c)\right] \frac{\partial^{2} \hat{\omega}}{\partial p^{2}}+2 \Lambda \frac{\partial \hat{\omega}}{\partial p}-\sigma_{0} \frac{k^{2}}{f_{0}^{2}}(\bar{u}-c) \hat{\omega}=0
$$


This equation with boundary conditions (A14) can only be solved numerically. An analytical solution can be obtained exactly if we are filtering out gravity waves using the quasi-geostrophic approximation (A8). In this case, we need to set the term $i k(\bar{u}-c){ }_{\Lambda} \hat{u}$ to zero. Consequently, we will obtain the following eigenvalue problem.

$$
(\bar{u}-c) \frac{\partial^{2} \hat{\omega}}{\partial p^{2}}+2 \Lambda \frac{\partial \hat{\omega}}{\partial p}-\sigma_{0} \frac{k^{2}}{f_{0}^{2}}(\bar{u}-c) \hat{\omega}=0, \hat{\omega}=0 \text { at } p=0 \text { and } p=p_{0}
$$

The wavenumber $k$ is a real number, while the wave phase velocity $c$ can be a complex quantity such that $c=c_{r}+i c_{i}$. The sign of $c_{i}$ determines whether the wave will grow $\left(c_{i}>0\right)$ or decay $\left(c_{i}<0\right)$. The condition $c_{i}>0$ indicates baroclinic instability with a growth rate defined as $k c_{i}$. The eigenvalue problem (A21) has a nontrivial solution when [41]

$$
c=\frac{\Lambda p_{0}}{2}[1 \pm \sqrt{1-R(\eta)}]
$$

where $\eta=p_{0} k \sqrt{\sigma_{0}} / f_{0}$ and $R(\eta)=4(\eta \operatorname{coth} \eta-1) / \eta^{2}$. If $R(\eta)>1$ then $c$ is a complex number (actually a complex-conjugate pair exists), and the condition of instability is $\eta<\eta_{c} \approx 2.3994$. From this condition we can derive the expression for the growth rate of unstable modes:

$$
k c_{i} \equiv \chi_{k}=\frac{\Lambda f_{0}}{2 \sqrt{\sigma_{0}}} \sqrt{\left|\eta^{2}-4(\eta \operatorname{coth} \eta-1)\right|}
$$

Appendix A.3. The $\beta$-Plane Model

Widely used in geophysical fluid dynamics, $\beta$-plane approximation allows for latitudinal variability of the Coriolis parameter, which is very important for accurate modelling of atmospheric wave motions on spherical earth. If $\varphi_{0}$ is a given latitude and $f_{0}$ is the Coriolis parameter at $\varphi_{0}$, then $f=f_{0}+\beta y$, where $\beta=\left(2 \Omega / a_{0}\right) \cos \varphi_{0}$. Here $\Omega$ is the angular speed of the Earth's rotation, and $a_{0}$ is the Earth's radius. Taking into account the $\beta$-plane approximation Equations (A1)-(A5) that describe the large-scale atmospheric dynamics can be transformed into the following two equations [21,37]:

$$
\begin{gathered}
\left(\frac{\partial}{\partial t}+u \frac{\partial}{\partial x}+v \frac{\partial}{\partial y}\right) \nabla^{2} \psi+\beta \frac{\partial \psi}{\partial x}=f_{0} \frac{\partial \omega}{\partial p} \\
\left(\frac{\partial}{\partial t}+u \frac{\partial}{\partial x}+v \frac{\partial}{\partial y}\right) \frac{\partial \psi}{\partial p}+\frac{\sigma_{0}}{f_{0}} \omega=0
\end{gathered}
$$

where $\psi=\Phi / f_{0}$ is a geostrophic streamfunction.

Note that the geostrophic wind velocity components, $u$ and $v$, can be expressed in terms of stream function as $u=-\partial \psi / \partial y$ and $v=-\partial \psi / \partial x$ respectively. The vertical boundary conditions are specified at the top $(p=0)$ and the bottom $\left(p=p_{o}\right)$ of the atmosphere and assume that the vertical velocity is equal to zero. Applying the Equation (A24) at the 250 and $750 \mathrm{hPa}$ levels designated as 1 and 2, respectively, and the Equation (A25) at the $500 \mathrm{hPa}$ level designated as 3/2, we obtain

$$
\begin{aligned}
& \left(\frac{\partial}{\partial t}+u_{1} \frac{\partial}{\partial x}+v_{1} \frac{\partial}{\partial y}\right) \nabla^{2} \psi_{1}+\beta \frac{\partial \psi_{1}}{\partial x}=\frac{f_{0}}{\Delta p} \omega_{3 / 2} \\
& \left(\frac{\partial}{\partial t}+u_{2} \frac{\partial}{\partial x}+v_{1} \frac{\partial}{\partial y}\right) \nabla^{2} \psi_{2}+\beta \frac{\partial \psi_{2}}{\partial x}=-\frac{f_{0}}{\Delta p} \omega_{3 / 2} \\
& \left(\frac{\partial}{\partial t}+u_{3 / 2} \frac{\partial}{\partial x}+v_{3 / 2} \frac{\partial}{\partial y}\right)\left(\psi_{1}-\psi_{2}\right)=\frac{\sigma_{0} \Delta p}{f_{0}} \omega_{3 / 2}
\end{aligned}
$$

where $\Delta p=500 \mathrm{hPa}$. 
Thus, we have a system of three Equations (A26)-(A28) in three variables $\psi_{1}, \psi_{2}$, and $\omega_{3 / 2}$. To explore the instability of the basic zonal flow with respect to infinitesimal perturbations, these equations are linearized around the basic state (A6) assuming that

$$
\psi_{1}=-u_{1} y+\psi_{1}^{\prime}(x, t) \psi_{2}=-u_{2} y+\psi_{2}^{\prime}(x, t) \omega_{3 / 2}=\omega_{3 / 2}^{\prime}(x, t)
$$

Substituting (A29) in the Equations (A26)-(A28) and defining the following notations

$$
u_{m}=\frac{1}{2}\left(u_{1}+u_{2}\right), u_{T}=\frac{1}{2}\left(u_{1}-u_{2}\right), \psi_{m}=\frac{1}{2}\left(\psi_{1}^{\prime}+\psi_{2}^{\prime}\right), \psi_{T}=\frac{1}{2}\left(\psi_{1}^{\prime}-\psi_{2}^{\prime}\right)
$$

after the elimination of the variable $\omega_{3 / 2}$, yields the perturbation equations:

$$
\begin{gathered}
\left(\frac{\partial}{\partial t}+u_{m} \frac{\partial}{\partial x}\right) \frac{\partial^{2} \psi_{m}}{\partial x^{2}}+\beta \frac{\partial \psi_{m}}{\partial x}+u_{T} \frac{\partial}{\partial x}\left(\frac{\partial^{2} \psi_{T}}{\partial x^{2}}\right)=0 \\
\left(\frac{\partial}{\partial t}+u_{m} \frac{\partial}{\partial x}\right)\left(\frac{\partial^{2} \psi_{T}}{\partial x^{2}}-2 \mu^{2} \psi_{T}\right)+\beta \frac{\partial \psi_{T}}{\partial x}+u_{T} \frac{\partial}{\partial x}\left(\frac{\partial^{2} \psi_{m}}{\partial x^{2}}+2 \mu^{2} \psi_{m}\right)=0
\end{gathered}
$$

where $\mu^{2}=f_{0}^{2} /\left[\sigma_{0}(\Delta p)^{2}\right]$.

We shall seek a normal modes solution:

$$
\psi_{m}=\Psi_{m} e^{i k(x-c t)}, \psi_{T}=\Psi_{T} e^{i k(x-c t)}
$$

where $\Psi_{m}$ and $\Psi_{T}$ are the perturbation amplitudes.

Substituting (A33) into the perturbation equations, we find that the phase speed of baroclinic waves satisfies the following equation:

$$
c=u_{m}-\frac{\beta}{k^{2}} \frac{k^{2}+\mu^{2}}{k^{2}+2 \mu^{2}} \pm \sqrt{D}
$$

where

$$
D=\frac{\beta^{2} \mu^{4}}{k^{2}\left(k^{2}+2 \mu^{2}\right)^{2}}+u_{T}^{2} \frac{k^{2}-2 \mu^{2}}{k^{2}+2 \mu^{2}}
$$

If the discriminant $D$ is negative, then the phase speed $c$ has an imaginary part $c_{i}$, and initially small perturbations will grow exponentially. In the two layer model, the baroclinic growth rate can be expressed as

$$
k c_{i} \equiv \chi_{k}=\frac{\sqrt{\left|\beta^{2} \mu^{4}+u_{T}^{2} k^{4}\left(k^{4}-4 \mu^{4}\right)\right|}}{k\left(k^{2}+2 \mu^{2}\right)}
$$

\section{References}

1. IPCC. Climate Change 2013: The Physical Science Basis. Contribution of Working Group I to the Fifth Assessment Report of the Intergovernmental Panel on Climate Change; Stocker, T.F., Qin, D., Plattner, G.-K., Tignor, M., Allen, S.K., Boschumg, J., Nauels, A., Xia, Y., Bex, V., Midgley, P.M., Eds.; Cambridge University Press: Cambridge, UK; New York, NY, USA, 2013; p. 1535.

2. WMO. Statement on the State of the Global Climate in 2018; WMO-No. 1233; World Meteorological Organization: Geneva, Switzerland, 2019; p. 39.

3. Fanglin, Y.; Arun, K.; Schlesinger, M.E.; Wang, W. Intensity of hydrological cycles in warmer climates. J. Clim. 2003, 16, 2419-2423.

4. Huntington, T.G. Evidence for intensification of the global water cycle: Review and synthesis. J. Hydrol. 2006, 319, 83-95. [CrossRef] 
5. Held, I.M.; Soden, B.J. Robust response of the hydrological cycle to global warming. J. Clim. 2006, 19, 5686-5699. [CrossRef]

6. Bengtsson, L. The global atmospheric water cycle. Environ. Res. Lett. 2010, 5, 025002. [CrossRef]

7. Grover, V.I. Impact of Climate Change on Water and Health; CRC Press: Boca Raton, FL, USA, 2012; p. 426.

8. Durack, P.J.; Wijffels, S.E.; Matear, R.J. Ocean salinities reveal strong global cycle intensification during 1950-2000. Science 2012, 336, 455-458. [CrossRef]

9. Bosilovich, M.G.; Robertson, F.R.; Chen, J. Global energy and water budgets in MERRA. J. Clim. 2011, 24, 5721-5739. [CrossRef]

10. Trenberth, K.E.; Fasullo, J.T. North American water and energy cycles. Geophys. Res. Lett. 2013, 40, $365-369$. [CrossRef]

11. Djebou, D.C.S.; Singh, V.P. Impact of climate change on the hydrologic cycle and implications for society. Environ. Soc. Psychol. 2016, 1, 36-49. [CrossRef]

12. Wentz, F.J.; Ricciardulli, L.; Hilburn, K.; Mears, C. How Much More Rain Will Global Warming Bring? Science 2007, 317, 233-235. [CrossRef]

13. Schmidt, G.A.; Ruedy, R.A.; Miller, R.L.; Lacis, A.A. Attribution of the present-day total greenhouse effect. J. Geophys. Res. 2010, 115, D20106. [CrossRef]

14. Chou, C.; Lan, C.-W. Changes in the annual range of precipitation under global warming. J. Clim. 2012, 25, 222-235. [CrossRef]

15. Behrangi, A.; Christens, M.; Richardson, M.; Lebsock, M.; Stephens, G.; Huffman, G.J.; Bolvin, D.; Adler, R.F.; Gardner, A.; Lambrigtsen, B.; et al. Status of high-latitude precipitation estimates from observations and reanalyses. J. Geophys. Res. Atmos. 2016, 121, 4468-4486. [CrossRef]

16. O'Gorman, P.A.; Schneider, T. The physical basis for increases in precipitation extremes in simulations of 21st century climate change. Proc. Natl. Acad. Sci. USA 2016, 106, 14773-14777. [CrossRef]

17. Putnam, A.E.; Broecker, W.S. Human-induced changes in the distribution of rainfall. Sci. Adv. 2017, 3, e1600871. [CrossRef]

18. Giorgi, F.; Raffaele, F.; Coppola, E. The response of precipitation characteristics to global warming from climate projections. Earth Syst. Dyn. 2019, 10, 73-89. [CrossRef]

19. Held, I.M.; Hoskins, B.J. Large-scale eddies and the general circulation of the atmosphere. Adv. Geophys. 1985, 28, 3-31. [CrossRef]

20. Matveev, L.T. The Theory of General Circulation of the Atmosphere and Earth's Climate; Hydrological and Meteorological Publisher: Leningrad, Russia, 1991; p. 296.

21. Holton, J.R.; Hakim, G.J. Introduction to Dynamic Meteorology, 5th ed.; Elsevier: Amsterdam, The Netherlands, 2012; p. 552.

22. Vallis, G.K. Atmospheric and Oceanic Fluid Dynamics: Fundamentals and Large-Scale Circulation; Cambridge University Press: Cambridge, UK, 2006; p. 745.

23. Randall, D. An Introduction to the Global Circulation of the Atmosphere; Princeton University Press: Princeton, NJ, USA, 2015; p. 456.

24. Lindzen, R.S. Dynamics in Atmospheric Physics; Cambridge University Press: Cambridge, UK, 1990; p. 320.

25. Gimeno, L.; Dominguez, F.; Nieto, R.; Trigo, R.; Drumond, A.; Reason, C.J.C.; Taschetto, A.; Ramos, A.M.; Kumar, R.; Marengo, J. Major mechanisms of atmospheric moisture transport and their role in extreme precipitation events. Annu. Rev. Environ. Resour. 2016, 41, 117-141. [CrossRef]

26. Zhang, Z.; Ralph, F.M.; Zheng, M. The relationship between extratropical cyclone strength and atmospheric river intensity and position. Geophy. Res. Lett. 2018, 46, 1814-1823. [CrossRef]

27. Lambert, S.J. The effect of enhanced greenhouse warming on winter cyclone frequencies and strengths. J. Clim. 1995, 8, 1447-1462. [CrossRef]

28. Geng, Q.; Sugi, M. Possible change of extratropical cyclone activity due to enhanced greenhouse gases and sulphate aerosols: Study with a high-resolution AGCM. J. Clim. 2003, 16, 2262-2274. [CrossRef]

29. Fyfe, J.C. Extratropical Southern Hemisphere cyclones: Harbingers of climate change. J. Clim. 2003, 16, 2802-2805. [CrossRef]

30. Yin, J.H. A consistent poleward shift of the storm tracks in simulations of 21st century climate. Geophys. Res. Lett. 2005, 32. [CrossRef] 
31. Lambert, S.J.; Fyfe, J.C. Changes in winter cyclone frequencies and strengths simulated in enhanced greenhouse warming experiments: Results from the models participating in the IPCC diagnostic exercise. Clim. Dyn. 2006, 26, 713-728. [CrossRef]

32. Bengtsson, L.; Hodges, K.I.; Roeckner, E. Storm tracks and climate change. J. Clim. 2006, 19, 3518-3543. [CrossRef]

33. Wu, Y.; Ting, M.; Seager, R.; Huang, H.-P.; Cane, M.A. Changes in storm tracks and energy transports in a warmer climate simulated by the GFDL CM2.1model. Clim. Dyn. 2011, 37, 53-72. [CrossRef]

34. Pfahl, S.; O'Gorman, P.A.; Singh, M.S. Extratropical cyclones in idealized simulations of changed climates. J. Clim. 2015, 28, 9373-9392. [CrossRef]

35. Charney, J.G. The dynamics of long waves in a baroclinic westerly current. J. Meteorol. 1947, 4, $136-162$. [CrossRef]

36. Eady, E.T. Long waves and cyclone waves. Tellus 1949, 1, 33-52. [CrossRef]

37. Phillips, N.A. Energy transformations and meridional circulations associated with simple baroclinic waves in a two-level, quasi-geostrophic model. Tellus 1954, 6, 273-286. [CrossRef]

38. Schultz, D.M.; Bosart, L.F.; Colle, B.A.; Davies, H.C.; Dearden, C.; Keyser, D.; Martius, O.; Roebber, P.J.; Steenburgh, W.J.; Volkert, H.; et al. Extratropical Cyclones: A Century of Research on Meteorology's Centerpiece. AMS Meteorol. Monogr. 2018, 59, 1-56. [CrossRef]

39. Lorenz, E.N. Available potential energy and the maintenance of the general circulation. Tellus 1955, 7, 157-167. [CrossRef]

40. Oort, A.H.; Peixoto, J.P. The annual cycle of the energetics of the atmosphere on a planetary scale. J. Geophys. Res. 1974, 79, 2705-2719. [CrossRef]

41. Oort, A.H. Global Atmospheric Circulation Statistics, 1958-1973; No. 14; US Department of Commerce; National Oceanic and Atmospheric Administration: Washington, DC, USA, 1983; pp. 180-226.

42. Dynmikov, V.P. Development of baroclinic instability in an atmosphere with a variable static stability parameter. Atmos. Ocean. Phys. 1978, 14, 352-356.

43. Grotjahn, R. Baroclinic Instability. In Encyclopedia of Atmospheric Sciences; Holton, J.R., Curry, J.A., Pyle, J.A., Eds.; Academic Press: Cambridge, MA, USA, 2003; pp. 419-467.

44. Lambaerts, J.; Lapeyre, G.; Zeitlin, V. Moist versus dry baroclinic instability in a simplified two-layer atmospheric model with condensation and latent heat release. J. Atmos. Sci. 2012, 69, 1405-1426. [CrossRef]

45. O'Gorman, P.A. The effective static stability experiences by eddies in a moist atmosphere. J. Atmos. Sci. 2011, 68, 75-90. [CrossRef]

46. Soldatenko, S.A. Numerical modelling of wave cyclogenesis in a moist baroclinic atmosphere. Meteorol. Hydrol. 1989, 7, 5-14.

47. Matveev, L.T.; Soldatenko, S.A. Effect of heat of condensation on the spectral energy distribution of baroclinically unstable modes. Earth Sci. Sect. 1989, 306, 70-74.

48. Kuo, Y.-H.; Shapiro, M.A.; Donall, E.G. The interaction between baroclinic and diabatic processes in a numerical simulation of a rapidly intensifying extratropical marine cyclone. Mon. Weather Rev. 1991, 119, 368-384. [CrossRef]

49. Stoelinga, M.T. A potential vorticity-based study of the role of diabatic heating and friction in a numerically simulated baroclinic cyclone. Mon. Weather Rev. 1996, 124, 849-874. [CrossRef]

50. Büeler, D.; Pfahl, S. Potential vorticity diagnostics to quantify effects of latent heating in extratropical cyclones. Part I: Methodology. J. Atmos. Sci. 2017, 74, 3567-3590. [CrossRef]

51. Letcher, T.M. Climate Change. In Observed Impacts on Planet Earth; Elsevier: Amsterdam, The Netherlands, $2009 ;$ p. 492.

52. Shepherd, T.G. Atmospheric circulation as a source of uncertainty in climate change projections. Nat. Geosci. 2015, 7, 703-708. [CrossRef]

53. Mann, M.E.; Rahmstorf, S.; Kornhuber, K.; Steinman, B.A.; Miller, S.K. Influence of anthropogenic climate change on planetary wave resonance and extreme weather events. Sci. Rep. 2017, 7, 45242. [CrossRef] [PubMed]

54. Screen, J.A.; Bracegirdle, T.J.; Simmonds, I. Polar climate change as manifest in atmospheric circulation. Curr. Clim. Chang. Rep. 2018, 4, 383-395. [CrossRef] [PubMed]

55. Bathiany, S.; Dakos, V.; Scheffer, M.; Lenton, T.M. Climate models predict increasing temperature variability in poor countries. Sci. Adv. 2018, 4, eaar5809. [CrossRef] [PubMed] 
56. Totz, S.; Petri, S.; Lehmann, J.; Peukert, E.; Coumou, D. Exploring the sensitivity of Northern Hemisphere atmospheric circulation to different surface temperature forcing using a statistical-dynamical atmospheric model. Nonlinear Process. Geophys. 2019, 26, 1-26. [CrossRef]

57. Lee, S. A theory for polar amplification from a general circulation perspective. Asia-Pac. J. Atmos. Sci. 2014, 50, 31-43. [CrossRef]

58. Pithan, F.; Thorsten, M. Arctic amplification dominated by temperature feedbacks in contemporary climate models. Nat. Geosci. 2014, 7, 181-184. [CrossRef]

59. Hernandez-Deckers, D.; Von Storch, J.-S. Impact of the warming patterns on global energetics. J. Clim. 2012, 25, 5223-5240. [CrossRef]

60. Frierson, D.M.W. Robust increases in midlatitude static stability in simulations of global warming. Geophys. Res. Lett. 2006, 33, L24816. [CrossRef]

61. Chou, C.; Wu, T.-C.; Tan, P.-H. Changes in gross moist stability in the tropics under global warming. Clim. Dyn. 2013, 41, 2481-2496. [CrossRef]

62. Shi, X.; Durran, D. Sensitivities of extreme precipitation to global warming are lower over mountains than over oceans and plains. J. Clim. 2016, 29, 4779-4791. [CrossRef]

63. Karamperidou, C. Surface temperature gradients as diagnostic indicators of midlatitude circulation dynamics. J. Clim. 2012, 25, 4154-4171. [CrossRef]

64. Meleshko, V.P.; Johannessen, O.M.; Baidin, A.V.; Pavlova, T.V.; Govorkova, V.A. Arctic amplification: Does it impact the polar jet stream? Tellus A 2016, 68, 32330. [CrossRef]

65. Arndt, N. Hydrosphere. In Encyclopedia of Astrobiology; Amils, R., Ed.; Springer: Berlin/Heidelberg, Germany, 2014. [CrossRef]

66. Kundzewicz, Z.W. Hydrosphere. In Encyclopedia of Ecology; Jørgensen, S.E., Fath, B.D., Eds.; Elsevier: Amsterdam, The Netherlands, 2008; pp. 1923-1930.

67. Matveev, L.T. Cloud Dynamics; Springer: Cham, The Netherlands, 1984; p. 356.

68. Hartmann, D.L. Global Physical Climatology; Academic Press: San Diego, CA, USA, 1994; p. 411.

69. Trenberth, K.E.; Fasulo, J.T.; Kiehl, J. Earth's global energy budget. Bull. Amer. Met. Soc. 2009, 90, $311-323$. [CrossRef]

70. Goosse, H.; Barriat, P.Y.; Lefebvre, W.; Loutre, M.F.; Zunz, V. Introduction to Climate Dynamics and Climate Modeling. 2008-2010. Available online: http://www.climate.be/textbook (accessed on 2 July 2019).

71. Lacis, A.A.; Hansen, J.E.; Russell, G.L.; Oinas, V.; Jonas, J. The role of long-lived greenhouse gases as principal LW control knob that governs the global surface temperature for past and future climate change. Tellus $B$ 2013, 65, 19734. [CrossRef]

72. Matveev, Y.L.; Matveev, L.T.; Soldatenko, S.A. Global Cloud Fields; Hydrometeoizdat: Leningrad, Russia, 1986; p. 279.

73. Peixoto, J.P.; Oort, A.H. Physics of Climate, 1st ed.; American Institute of Physics: College Park, MD, USA, 1992; p. 520.

74. Naakka, T.; Nygård, T.; Vihma, T.; Sedlar, J.; Graversen, R. Atmospheric moisture transport between mid-latitudes and the Arctic: Regional, seasonal and vertical distributions. Int. J. Clim. 2019, 39, 2862-2879. [CrossRef]

75. Tsukernik, M.; Lynch, A. Atmospheric meridional moisture flux over the Southern Ocean: A story of the Amundsen Sea. J. Clim. 2013, 26, 8055-8064. [CrossRef]

76. Dufour, A.; Zolina, O.; Gulev, S.K. Atmospheric moisture transport to the Arctic: Assessment of reanalyses and analysis of transport components. J. Clim. 2016, 29, 5061-5081. [CrossRef]

77. Trenberth, K.E.; Stepaniak, D.P. Covariability of components of poleward atmospheric energy transports on seasonal and interannual timescales. J. Clim. 2003, 16, 3691-3705. [CrossRef]

78. Wetzel, A.N.; Smith, L.M.; Stechmann, S.N. Moisture transport due to baroclinic waves: Linear analysis of precipitating quasi-geostrophic dynamics. Math. Clim. Weather 2017, 3, 28-50. [CrossRef]

79. Soldatenko, S. Influence of atmospheric static stability and meridional temperature gradient on the growth in amplitude of synoptic-scale unstable waves. Atmos. Ocean. Phys. 2014, 50, 554-561. [CrossRef]

80. Soldatenko, S.A.; Chichkine, D. Climate Model Sensitivity with Respect to Parameters and External Forcing. In Topics in Climate Modeling; Hromadka, T., Rao, P., Eds.; Intech Open: Rijeka, Croatia, 2016; pp. 105-135. [CrossRef] 
81. Gastineau, G.; Soden, B.J. Model projected changes of extreme wind events in response to global warming. Geophys. Res. Lett. 2009, 36, L10810. [CrossRef]

82. Schneider, T.; Mbengue, C. Storm-track shifts under climate change: Toward a mechanistic understanding using baroclinic mean available potential energy. J. Atmos. Sci. 2017, 74, 93-110.

83. Chemke, R. Atmospheric energy transfer response to global warming. Q. J. R. Meteorol. Soc. 2017, 143, 2296-2308. [CrossRef]

84. Akperov, M.G.; Mokhov, I.I. Estimates of the sensitivity of cyclonic activity in the troposphere of extratropical latitudes to changes in the temperature regime. Atmos. Ocean. Phys. 2013, 49, 129-136. [CrossRef]

85. Mokhov, I.I.; Doronina, T.N.; Gryanik, V.M.; Khairullin, R.R.; Korovkina, L.V.; Lagun, V.E. Extratropical Cyclones and Anticyclones: Tendencies of Changes. In the Life Cycles of Extratropical Cyclones; Gronas, S., Hapiro, M.A., Eds.; Geophysical Institute, University of Bergen: Bergen, Norway, 1994; pp. 56-60.

86. Mokhov, I.I.; Mokhov, O.I.; Petukhov, V.K. Influence of global climate change on the vortex activity of the atmosphere. Atmos. Ocean. Phys. 1992, 28, 11-26.

87. Dymnikov, V.P.; Fomenko, A.A. On the spectral distribution of unstable modes in the general atmospheric circulation model. Atmos. Ocean. Phys. 1981, 17, 675-679.

88. Budyko, M.I. The effect of solar radiation variations on the climate of the Earth. Tellus 1969, 21, 611-619. [CrossRef]

89. Harvey, B.; Shaffrey, L.; Woollings, T. Equator-to-pole temperature differences and the extra-tropical storm track responses of the CMIP5 climate models. Clim. Dyn. 2014, 43, 1171-1182. [CrossRef]

90. Hansen, J.; Sato, M.; Kharecha, P.; von Schuckmann, K. Earth's energy imbalance and implications. Atmos. Chem. Phys. 2011, 11, 13421-13449. [CrossRef]

91. Von Schuckmann, K.; Palmer, M.D.; Trenberth, K.E.; Cazenave, A.; Chambers, D.; Champollion, M.; Hansen, J.; Josey, S.A.; Loeb, N.; Mathieu, P.-P.; et al. An imperative to monitor Earth's energy imbalance. Nat. Clim. Chang. 2016, 6, 138-144. [CrossRef]

92. Cohen, J.; Screen, J.A.; Furtado, J.C.; Barlow, M.; Whittleston, D.; Coumou, D.; Francis, J.; Dethloff, K.; Entekhabi, D.; Overland, J.; et al. Recent Arctic amplification and extreme mid-latitude weather. Nat. Gensci. 2014, 7, 627-637. [CrossRef]

93. Walsh, J.E. Intensified warming of the Arctic: Causes and impacts on middle latitudes. Glob. Planet. Chang. 2014, 117, 52-63. [CrossRef]

94. Lee, S.H.; Williams, P.D.; Frame, T.H.A. Increased shear in the North Atlantic upper-level jet stream over the past four decades. Nature 2019, 572, 639-642. [CrossRef] [PubMed]

95. Lorenz, D.; DeWeaver, E.T. Tropopause height and zonal wind response to global warming in the IPCC scenario integrations. J. Geophys. Res. 2007, 112. [CrossRef]

96. Hassanzadeh, P.; Kuang, Z.; Farre, B.F. Responses of midlatitude blocks and wave amplitude to changes in the meridional temperature gradient in an idealized dry GCM. Geophys. Res. Lett. 2014, 41, 5223-5232. [CrossRef]

97. Francis, J.A.; Vavrus, S.J. Evidence linking Arctic amplification to extreme weather in mid-latitudes. Geophys. Res. Lett. 2012, 39, L06801. [CrossRef]

98. Yuval, J.; Kaspri, Y. Eddy activity sensitivity to changes in the vertical structure of baroclinicity. J. Atmos. Sci. 2016, 73, 1709-1726. [CrossRef]

99. Marshall, J.; Plumb, R.A. Atmosphere, Ocean and Climate Dynamics: An Introductory Text; International Geophysics Series; Academic Press: Cambridge, MA, USA, 2007; p. 344.

(C) 2019 by the author. Licensee MDPI, Basel, Switzerland. This article is an open access article distributed under the terms and conditions of the Creative Commons Attribution (CC BY) license (http://creativecommons.org/licenses/by/4.0/). 